Guidelines

\title{
Diagnosis of chronic anaemia in gastrointestinal disorders: A guideline by the Italian Association of Hospital Gastroenterologists and Endoscopists (AIGO) and the Italian Society of Paediatric Gastroenterology Hepatology and Nutrition (SIGENP)
}

\author{
Luca Elli $^{\mathrm{a}, *}$, Lorenzo Norsa ${ }^{\mathrm{b}}$, Angelo Zullo $^{\mathrm{c}}$, Antonio Carroccio ${ }^{\mathrm{d}, \mathrm{e}}$, Carlo Girelli $^{\mathrm{f}}$, \\ Salvatore Oliva ${ }^{\mathrm{g}}$, Claudio Romano $^{\mathrm{h}}$, Gioacchino Leandro ${ }^{\mathrm{i}}$, Massimo Bellini ${ }^{\mathrm{j}}$, \\ Riccardo Marmo ${ }^{k}$, Marco Soncini ${ }^{1}$, Fabio Monica ${ }^{m}$, Vincenzo De Francesco ${ }^{n}$, \\ Emma Paulon $^{\mathrm{m}}$, Maria Domenica Cappellini ${ }^{\mathrm{o}}, \mathrm{p}$, Irene Motta ${ }^{\mathrm{o}, \mathrm{p}}$, Francesca Ferretti ${ }^{\mathrm{a}}$, \\ Stefania Orlando ${ }^{a}$, Pasquale Mansueto ${ }^{\mathrm{e}}$, Elisabetta Buscarini ${ }^{\mathrm{q}}$, Guido Manfredi ${ }^{\mathrm{q}}$, \\ Carlo Agostoni $^{\mathrm{r}, \mathrm{p}}$, Carolina Tomba ${ }^{\mathrm{s}}$, Renato Cannizzaro ${ }^{\mathrm{t}}$
}

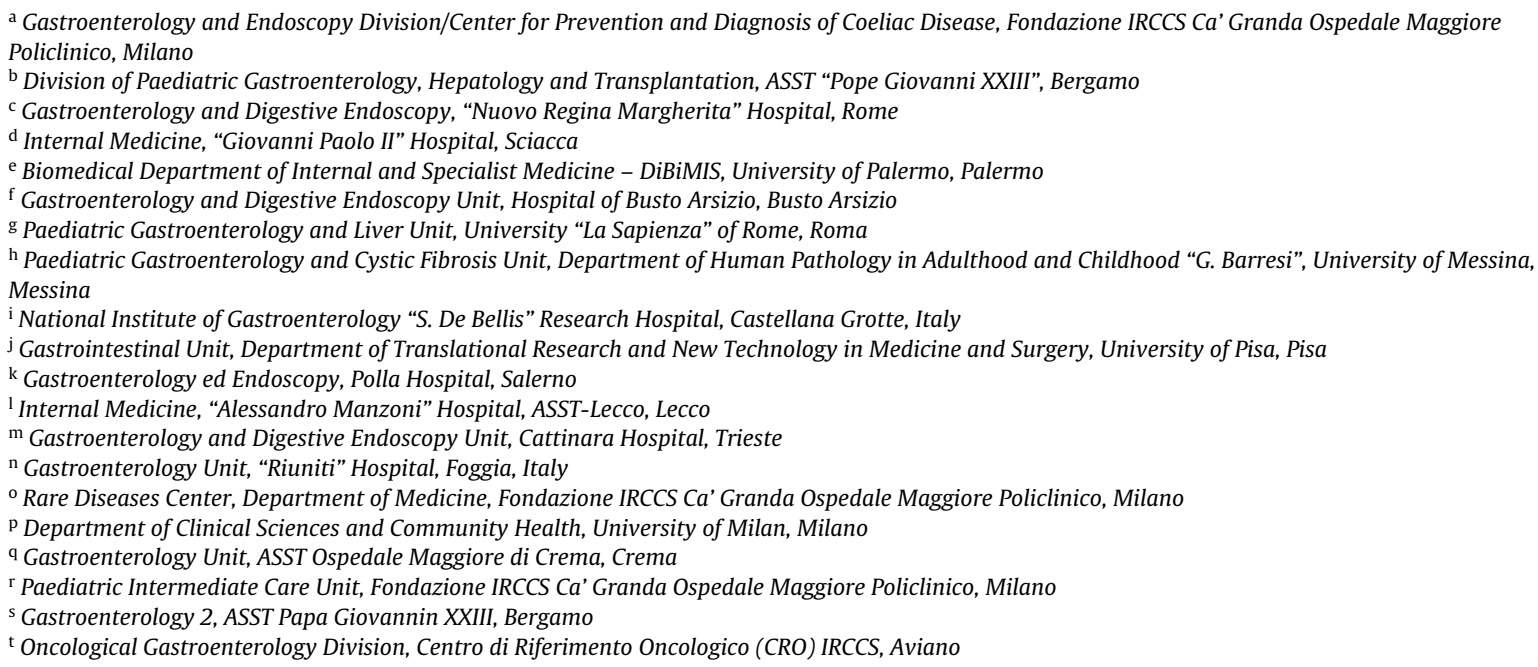

\section{A R T I C L E I N F O}

\section{Article history:}

Received 14 December 2018

Accepted 29 January 2019

Available online $\mathrm{xxx}$

\section{Keywords:}

Anaemia

Iron deficiency

Endoscopy

Small bowel

H. pylori

Celiac disease

Inflammatory bowel disease

\begin{abstract}
A B S T R A C T
Anaemia is a common pathologic condition, present in almost $5 \%$ of the adult population. Iron deficiency is the most common cause; other mechanisms can be involved, making anaemia a multi-factorial disorder in most cases. Anaemia being a frequent manifestation in the diseases of the gastrointestinal tract, patients are often referred to gastroenterologists. Furthermore, upper and lower endoscopy and enteroscopy are pivotal to the diagnostic roadmap of anaemia. In spite of its relevance in the daily clinical practice, there is a limited number of gastroenterological guidelines dedicated to the diagnosis of anaemia. For this reason, the Italian Association of Hospital Gastroenterologists and Endoscopists and the Italian Society of Paediatric Gastroenterology, Hepatology and Nutrition commissioned a panel of experts to prepare a specific guideline on anaemia and its diagnostic roadmap in the gastroenterological scenario. The panel also discussed about the potential involvement of gastroenterologists and endoscopists in the management of patients with anaemia, with particular attention to the correct use of investigations. The panel
\end{abstract}

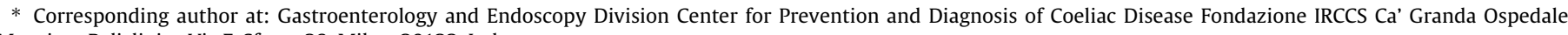
Maggiore Policlinico Via F. Sforza 28, Milan, 20122, Italy.

E-mail address: luca.elli@policlinico.mi.it (L. Elli). 
paid particular attention to practical issues with the aim to support gastroenterologists in their clinical practice when dealing with patients with anaemia.

(c) 2019 Editrice Gastroenterologica Italiana S.r.l. Published by Elsevier Ltd. All rights reserved.

\section{Introduction}

Anaemia is a worldwide pathological condition that affects almost $5 \%$ of the adult population in the Western countries, iron deficiency (ID) being its most frequent cause [1,2]. The disorders of the gastrointestinal (GI) tract frequently lead to an anaemic status and thus patients are frequently referred to a gastroenterologist $[3,4]$. GI diseases can induce anaemia through different mechanisms: malabsorption (e.g. coeliac disease, $\mathrm{CD}$ ) [5], obscure bleeding (e.g. intestinal vascular malformations) [6], chronic inflammation (e.g. inflammatory bowel disease) [7], autoimmune reactions against specific factors (e.g. pernicious anaemia) [8] or, frequently, as a consequence of combined mechanisms. Furthermore, anaemia is a major indication for endoscopy (upper, lower and, in specific cases, enteroscopy) and thus, gastroenterologists should be aware about the differential diagnosis, blood and faecal tests, and diagnostic procedures to use when facing anaemic patients [3]. In spite of its relevance in daily clinical practice, only a few guidelines specifically written for the gastroenterological setting have been published, none of which from the Italian gastroenterological societies [3,9-11].

The present guideline aims to support gastroenterologists in their practice when dealing with patients with anaemia. Apart the necessity to develop a national guideline and differently from the other published guidelines, the proposed one focused on the role of the gastroenterologists and endoscopists in the diagnostic process of patients with anaemia presenting specific sections and including the pediatric and adult settings.

\section{Methods}

In March 2017 the Italian Association of Hospital Gastroenterologists and Endoscopists (AIGO), supported by the Italian Society of Paediatric Gastroenterology, Hepatology and Nutrition (SIGNEP), commissioned a panel of experts, with the aim to prepare a guideline to support specialists in the diagnosis of anaemia related to GI tract diseases. Furthermore, the panel was supported by two members of the Italian Society of Hematology (MDC and IM). The specific tasks carried out by the panel members are reported in the Supplementary File 1 herewith provided.

Key questions were developed following the PICO format [12] and voted. A PubMed/EMBASE search for English-written articles, with no time limits and using appropriate MeSH terms (Supplementary File 1) was performed. Regular conference calls, web-based exchanges and two intermediate meetings were scheduled. The levels of evidence and recommendations were defined for every part of the statement according to the GRADE system [13]. At the end, the panel voted the statements. For clearness, a list of abbreviation is reported in supplementary file 2 .

\section{Classification, diagnosis and clinical biomarkers of anaemia}

Anaemia is defined as haemoglobin (Hb) levels $<12 \mathrm{~g} / \mathrm{dl}$ in women and $<13 \mathrm{~g} / \mathrm{dl}$ in men [1]. It is found in one third of the world population and children aged $<5$ years and women have the highest burden. Half of the cases of anaemia worldwide are due to ID [14]. For practical purposes, anaemia can be classified on the basis of either the mean cellular volume (MCV), or the underlying pathological mechanism (hypoproliferative, maturation abnormalities, increased destruction of red cells) or the patient's clinical history (acquired or congenital, acute or chronic). In the presence of low MCV ( $<80 \mathrm{fl}$ ), the iron status (serum iron, transferrin, transferrin saturation or total iron capacity and ferritin) is necessary to identify ID anaemia (IDA) [15]. However, a normal MCV level does not exclude the presence of ID, the same way as in chronic inflammatory diseases. Recently, a panel of experts defined ID in chronic inflammatory disorders as "a health-related condition in which iron availability is insufficient to meet the body needs" and the following cut-off values have been proposed for diagnosis: i) serum ferritin $<100 \mathrm{mcg} / \mathrm{L}$ or transferrin saturation (TSAT) $<20 \%$; ii) serum ferritin between $100 \mathrm{mcg} / \mathrm{L}$ and $300 \mathrm{mcg} / \mathrm{L}$ and TSAT <20\% [16]. A high level of $\mathrm{MCV}$ ( $>100 \mathrm{fl}$ ) is found in "megaloblastic anaemia", usually due to nutritional deficiency or malabsorption of vitamin $B_{12}$ and/or folate [17]. In order to evaluate the underlying pathological mechanism, reticulocyte count, a marker of red blood cell production can direct further investigation. Reticulocytes are usually expressed as percentage of the number of red blood cells or as an absolute number, but the most appropriate parameter is the reticulocyte index (RI): Reticulocyte $\% \times \mathrm{Ht} \times$ normal $45 \%^{-1}$ (for example in case of reticulocyte $2 \%$, Ht $45 \%$ the RI is 2 ) which is corrected for the severity of anaemia. Several novel serological bio-markers are today available to diagnose, classify and evaluate the therapeutic response (Table 1).

\subsection{Faecal occult blood test}

Noteworthy, the use of the stool-based tests is frequently inappropriately used in clinical practice. Thanks to their diagnostic accuracy and non-invasiveness, they are widely carried out in primary care and recommended as first-line screening tools for colorectal cancer (CRC) $[18,19]$. The most frequently used stoolbased CRC screening tests are the guaiac-based faecal occult blood test (gFOBT), and the faecal immunochemical test (FIT). Stoolbased tests are a screening tool and, therefore, should be reserved for asymptomatic subjects within the average-risk cohort for CRC screening. The inadequate use of stool-based tests (e.g. outside the age criteria or on subjects with a life expectancy less than 10 years or patients with a family history of CRC who should better undergo direct colonoscopy) increases the number of inappropriate colonoscopies, the amount of costs and overall exposure to potential endoscopic complications [20]. Moreover, stool-based screening tests should not be used in symptomatic subjects such as those reporting anaemia, ID, overt gastrointestinal bleeding, non-bloody diarrhea, abdominal pain or change in bowel habits, as their use postpones the necessary endoscopic investigation, thus leading to diagnostic delays [21,22].

\subsubsection{Panel recommendations}

- Stool-based tests (FOBT or FIT) should not be carried out on patients with anaemia to investigate its origin (strong recommendation, moderate level of evidence).

Vote result: strongly agree $60 \%$, agree $26.7 \%$, moderately agree $6.7 \%$, moderately disagree $0 \%$, disagree $0 \%$, strongly disagree $6.7 \%$ 
Table 1

Serological biomarkers available for diagnosing, classifying and managing anaemia.

\begin{tabular}{|c|c|c|}
\hline Biomarker & Normal range & Clinical utility \\
\hline Haemoglobin & $\begin{array}{l}\text { Adult Male: } 13-18 \mathrm{~g} / \mathrm{dl} \text {. } \\
\text { Adult Female: } 12-16 \mathrm{~g} / \mathrm{dl} \text {. }\end{array}$ & $\begin{array}{l}\text { To diagnose anaemia. } \\
\text { To evaluate therapeutic response. }\end{array}$ \\
\hline Mean cellular volume, MCV & $80-100 \mathrm{fl}$ & To define Normo-/Macro-/Micro-cytic anaemia. \\
\hline Mean corpuscolar haemoglobin, $\mathrm{MCH}$ & $26-32 \mathrm{pg} /$ cell & To define Normo-/Iper-/Ipo-chromic anemia. \\
\hline Mean corpuscolar haemoglobin concentration, $\mathrm{MCHC}$ & $32 \%-36 \%$ & To define Normo-/Iper-/Ipo-chromic anemia. \\
\hline Red blood cell distribution width, RDW & $11.8 \%-15.6 \%$ & $\begin{array}{l}\text { To evaluate RBC distribution. If increased: suspicion of concomitant } \\
\text { presence of different populations of } \mathrm{RBC} \text { (as in iron and/or folate } \\
\text { and/or vitamin } \mathrm{B}_{12} \text { deficiency) or presence of reticulocytes. }\end{array}$ \\
\hline Reticulocytes & $\begin{array}{l}\text { Absolute values: } 25-75 \times 10^{9} / 1 \\
\text { Reticulocytes Index: } 0.5 \%-2.5 \%\end{array}$ & Index of erythropoietic activity. \\
\hline Ferritin & $20-200 \mathrm{mcg} / \mathrm{l}$ & $\begin{array}{l}\text { It reflects the total amount of iron deposits in the body and is essential } \\
\text { to define iron deficiency. Inflammatory protein. }\end{array}$ \\
\hline Transferrin & $240-360 \mathrm{mg} / \mathrm{dl}$ & $\begin{array}{l}\text { Main iron transport protein in the bloodstream. Usually increased in } \\
\text { iron deficiency anemia, pregnancy, estrogen administration and } \\
\text { decreased during iron overload, malnutrition, inflammatory condition } \\
\text { Useful to distinguish anaemia due to chronic disorders from iron } \\
\text { deficiency anaemia. }\end{array}$ \\
\hline Total iron binding capacity, TIBC & $240-450 \mathrm{mcg} / \mathrm{dl}$ & $\begin{array}{l}\text { Indirect measurement of transferrin's capacity of binding iron. } \\
\text { Increased in iron deficiency. }\end{array}$ \\
\hline Transferrin saturation, TSAT & males: $20 \%-50 \%$ & Sideraemia/TIBC $\times 100$ \\
\hline & females: $15 \%-50 \%$ & $\begin{array}{l}\text { Indirect measurement of transferrin's capacity of binding iron. Usually } \\
\text { decrease in iron deficiency and increase in iron overload. }\end{array}$ \\
\hline Sideraemia & $53-167 \mathrm{mcg} / \mathrm{dl}$ & $\begin{array}{l}\text { Not indicative of body deposits. If decreased: severe iron deficiency, } \\
\text { chronic and/or neoplastic and/or inflammatory diseases. Limited } \\
\text { diagnostic value (significant decrease only when the body deposits are } \\
\text { almost depleted). }\end{array}$ \\
\hline Soluble transferrin receptor & $4-7 \mathrm{mg} / \mathrm{l}$ & $\begin{array}{l}\text { Increased in hyperplastic erythropoiesis and/or iron } \\
\text { deficiency.Decreased in hypoplastic erythropoiesis Useful to } \\
\text { distinguish iron deficiency anaemia from anaemia caused by chronic } \\
\text { or inflammatory diseases. }\end{array}$ \\
\hline Hepcidin & $\begin{array}{l}\text { Variable values (based on different } \\
\text { laboratory methods, nostandardized } \\
\text { normal values are available) }\end{array}$ & $\begin{array}{l}\text { Liver peptide hormone. It regulates iron homeostasis. Acute phase } \\
\text { protein. Increased in chronic inflammatory conditions. }\end{array}$ \\
\hline Zinc Protoporphyrin & $\begin{array}{l}\text { Variable values (based on different } \\
\text { laboratory methods, no standardized } \\
\text { normal values are available) }\end{array}$ & $\begin{array}{l}\text { Increased in erythropoiesis disorders, including hypochromic anaemia } \\
\text { Not useful for differentiating iron deficiency anaemia from chronic } \\
\text { inflammation anaemia. }\end{array}$ \\
\hline Erythropoietin & $2-25 \mathrm{U} / \mathrm{l}$ & $\begin{array}{l}\text { Hormone stimulating erithropoeiesis. Decreased in chronic kidney } \\
\text { disease. }\end{array}$ \\
\hline Vitamin B12 & $150-900 \mathrm{pg} / \mathrm{ml}$ & Decreased in megaloblastic anaemia. \\
\hline Folate & $2.7-17 \mathrm{ng} / \mathrm{ml}$ & Decreased in megaloblastic anaemia. \\
\hline Haptoglobin & $32-205 \mathrm{mg} / \mathrm{dl}$ & $\begin{array}{l}\text { Protein binding the extra-globular haemoglobin and conveying it to } \\
\text { the reticuloendothelial system. Decreased in hemolytic anemia. }\end{array}$ \\
\hline Bilirubin & $\begin{array}{l}\text { Total: } 0.3-1.0 \mathrm{mg} / \mathrm{dl} \text { Direct: } \\
0.0-0.4 \mathrm{mg} / \mathrm{dl} \text { Indirect: } 0.1-1.0 \mathrm{mg} / \mathrm{dl}\end{array}$ & Increased in hemolytic anaemia (total and indirect). \\
\hline Lactate dehydrogenase, LDH & $135-225 \mathrm{U} / 1$ & Intra-cytoplasmatic enzyme. Increased in haemolytic anemia. \\
\hline Urinary hemoglobin & Absent & Increased in haemolytic anaemia. \\
\hline Urinary urobilinogen & $<0.2 \mathrm{EU} / \mathrm{dl}$ & Increased in haemolytic anaemia. \\
\hline
\end{tabular}

\section{Role of endoscopy}

\subsection{Upper endoscopy}

Although invasive, upper endoscopy is widely carried out in the Western countries. Considering the demographic characteristics and clinical history of a patient, it is possible to schedule an adequate strategy and a correct timing for upper endoscopy. IDA in pre-menopausal women is usually attributed to excessive menstrual blood loss ( $9 \%$ to $14 \%$ of all women) [23] or to an inadequate dietary intake [24]. In this subset of subjects, if the gynaecological work-up is unremarkable and patients do not respond to iron replacement therapy (IRT), upper endoscopy should firstly be performed to exclude occult blood bleeding from gastric or duodenal GI lesions [25-27]. Significant upper GI tract lesions are present in up to $30 \%$ of pre-menopausal women with IDA, as erosive lesions caused by $H$. pylori or NSAID use (55\%-68\% of cases); upper GI cancers are very rare $(0 \%-3 \%)$ [27]. All pre-menopausal women with anaemia should be screened for coeliac disease (CD), which is present in up to $6 \%$ of them [25] and duodenal biopsies should be taken.
An increased risk of diagnosing GI cancer within the subsequent two years was observed among men and post-menopausal women with IDA (in $6 \%$ of patients older than 50 years and in $9 \%$ of women older 65 years) [28]. With these groups of patients, GI sources of bleeding should be excluded, as the first step of the diagnostic flowchart. The current recommendations from the American Family Physicians [29] support upper endoscopy as the first investigation; however, there are no clear guidelines about the correct sequence of the endoscopic investigations [30]. In patients over 50 years, the colonoscopy-first strategy should be preferred [31].

The existence of site-specific symptoms can be a disease predictor, suggesting the route of insertion (upper or lower) [32]. If necessary, upper and lower GI endoscopy can be performed in the same session and the combination of both exams is highly specific to localize any bleeding GI sites that cause anaemia [33,34].

Upper endoscopy can find the cause of digestive bleeding in about $90 \%$ of symptomatic cases; its diagnostic yield (DY) drops to $62 \%-70 \%$ in case of asymptomatic patients [32]. Noteworthy, lesions can be missed at the first investigation in about $10 \%$ of all upper endoscopies [35]; superficial lesions in hiatal hernia or vascular ectasia of the upper GI tract are often underdiagnosed and 
can be difficult to detect. Simultaneous lesions of both the upper and lower gastrointestinal tracts have been found in 9\% [36]. An upper GI bleeding source is found in more than one third of the patients with IDA, and most of the lesions are benign [37]. It is important to consider also the existence of non-bleeding sources of IDA, including: CD, gastric surgery, atrophic gastritis, $H$. pylori infection, autoimmune gastritis [37]. For these reasons upper GI endoscopy should include random gastric antral and fund biopsies in addition to duodenal biopsies [38].

It is still unclear whether site-specific symptoms (in the upper and/or lower GI tract) are really predictors of a bleeding lesion at the corresponding site $[39,40,41]$. Predictors comprise: abdominal symptoms, weight loss ( $\Delta-10 \%$ of body weight), and haemoglobin level $<10 \mathrm{~g} / \mathrm{dl}$ with MCV $<72 \mathrm{fl}$. The prevalence of GI cancers in patients with non-ID anaemia is low as compared with patients with IDA (up to 15\%) [42]. Although the ferritin cut-off value to be considered in anaemic patients as a predictor of malignancy is not clear, evaluating the GI tract of patients with ferritin levels higher than $100 \mathrm{ng} / \mathrm{ml}$ (in the absence of an acute phase response) by endoscopy should not be considered, but the evidence available is still scanty $[43,44]$.

If upper endoscopy is normal and anaemia is not severe without alarm symptoms, oral IRT and a watch-and-wait strategy can be carried out. For patients that do not respond to IRT or with suspected serious illness, a second look by endoscopy may be justified [45].

\subsubsection{Panel recommendations}

- Upper endoscopy should be performed on pre-menopausal women, in case of failure of the iron replacement therapy (strong recommendation, low level of evidence).

Vote result: strongly agree $33.3 \%$, agree $60 \%$, moderately agree $6.7 \%$, moderately disagree $0 \%$, disagree $0 \%$, strongly disagree $0 \%$

- In case of macroscopically negative upper endoscopy, gastric and duodenal biopsies should be taken in order to exclude coeliac disease and autoimmune gastritis (strong recommendation, low level of evidence).

Vote result: strongly agree $53.3 \%$, agree $40 \%$, moderately agree $6.7 \%$, moderately disagree $0 \%$, disagree $0 \%$, strongly disagree $0 \%$

- Upper endoscopy is often complementary to colonoscopy in the search of a bleeding source. When a source is found in patients aged over 50 years, we suggest avoiding colonoscopy only in the presence of an upper GI cancer (weak recommendation, low level of evidence)

Vote result: strongly agree 40\%, agree 46.7\%, moderately agree $13.3 \%$, moderately disagree $0 \%$, disagree $0 \%$, strongly disagree $0 \%$

\subsection{Lower endoscopy}

Blood loss from the GI tract is the most frequent cause of IDA in men and post-menopausal women [46]. Among post-menopausal women and adult men with IDA, upper endoscopy and colonoscopy reveal upper GI lesions in $7 \%-72 \%$, lower GI lesions in $7 \%-58 \%$, and lesions affecting both tracts in $0 \%-29 \%$ of the cases. The main colonoscopy findings are: colorectal cancer (0\%-34\%), adenomas $(1 \%-27 \%)$, inflammatory bowel disease $(0.4 \%-10 \%)$ and angiodysplasia (0\%-7\%) [47]. In pre-menopausal women with IDA the DY of endoscopic investigations is up to 95\% for upper GI lesions and up to $16 \%$ for lower GI lesions. In this group the prevalence of cancer is low (0\%-6\%) and mostly found in patients aged over 40 years [28]. Based on these findings [48] and the high prevalence of
GI malignancies in adults, the current guidelines recommend that upper and lower GI investigations should be offered to patients aged $>50$ years [3]. As previously mentioned, the order of the investigations should be guided by the suggestive symptoms (when present), although colonoscopy should be prioritized for patients aged $>50$ years, because of the high prevalence (roughly $10 \%$ ) of CRC in this scenario [49].

In pre-menopausal women presenting IDA GI bleedings have been found, mainly, in the upper GI tract while lesions of the lower GI tract have been infrequently described [47]. The guidelines from the British Society of Gastroenterology (BSG) recommend colonoscopy for pre-menopausal $<50$ years old women with lower abdominal symptoms, a family history for CRC or persistent IDA in spite of IRT [3]. Furthermore, despite the lack of evidence, the BSG guidelines recommend that young men ( $<50$ years old) with IDA should be investigated in the same manner as older men [3]. This recommendation is weakly supported by the few published studies, which have confirmed the infrequent presence of any significant lower GI pathology in young men with IDA [50-52]. A recent study compared colonoscopy findings in young patients (both male and female, aged 40-49 years) to the average-risk of individuals aged 50-54 years undergoing colonoscopy. It concluded that young patients with IDA have a significant lower risk of advanced neoplasia, therefore it would be less likely that they were to benefit from colonoscopy [52]. Noteworthy, the possible increase in the DY by adding ileoscopy during standard colonoscopy has not been specifically investigated in the setting of anaemia; however, the potential usefulness of ileitis detection in this setting represents a potential indication.

\subsubsection{Panel recommendations}

- Colonoscopy should be performed on all men and post-menopausal women with IDA (strong recommendation, low quality of evidence).

Vote result: strongly agree $66.7 \%$, agree $26.7 \%$, moderately agree $6.7 \%$, moderately disagree $0 \%$, disagree $0 \%$, strongly disagree $0 \%$

- The visualization of the distal ileum during standard endoscopy should be performed to reveal the presence of ileitis (conditional recommendation, low quality of evidence).

Vote result: strongly agree $26.7 \%$, agree $60 \%$, moderately agree $13.3 \%$, moderately disagree $0 \%$, disagree $0 \%$, strongly disagree $0 \%$

- Colonoscopy should be performed on pre-menopausal women with IDA in one or more of the following scenarios: proven absence of a gynaecological cause of IDA, strong family history for CRC, presence of lower abdominal symptoms, failure to respond to IRT (strong recommendation, low quality of evidence).

Vote result: strongly agree $53.3 \%$, agree $46.7 \%$, moderately agree $0 \%$, moderately disagree $0 \%$, disagree $0 \%$, strongly disagree $0 \%$

\subsection{Small-bowel endoscopy}

In case of normal findings at upper and lower gastrointestinal endoscopy, the small bowel (SB) of anaemic patients, should be deeply investigated [53-57]. A systematic review with metaanalysis, including 24 studies and 1960 patients with IDA, has provided an overall pooled DY of capsule enteroscopy (CE) of $47 \%$ (95\% CI, 42-52) [58]. In 4 studies (264 patients) focusing on patients with IDA, the DY was $66 \%(95 \% \mathrm{CI}, 61-72)$. The most frequently detected lesions were: vascular (31\%), inflammatory (18\%), and mass/tumor (8\%). Noteworthy, a similar finding frequency was for patients less than 50 years of age, underlying the usefulness of $\mathrm{CE}$ 
for young patients [59]. Furthermore, in case of normal CE results, a watch-and-wait strategy with scheduled clinical re-evaluation is advised by recent guidelines and meta-analyses [53,55-59].

Endoscopic SB exploration is nowadays feasible by means of CE (for diagnostic purposes) and device-assisted enteroscopy (DAE, diagnostic and therapeutic options). A meta-analysis [60] compared the DY of CE vs. double-balloon enteroscopy (DBE) in patients with obscure GI bleeding. The authors pooled the data from 10 studies: the DY was $62 \%$ (95\% CI, 47-76) for CE and $56 \%$ (95\% CI, 48-62) for DBE, with an odds ratio for CE compared with DBE of $1.4(95 \% \mathrm{CI}$, $0.9-2.2)$. A sub-group analysis demonstrated that the DY of a CEDBE sequential approach was $75 \%$ (95\% CI, 60-90), with an odds ratio of $1.8(95 \% \mathrm{CI}, 1-3)$. Conversely, the DY of DBE after a negative CE was 27\% (95\% CI, 16-38). Moreover, the CE finding facilitates the decision about the route of insertion and is associated with better long-term outcomes, decreased number of complications and more effective use of endoscopic resources [61].

In a meta-analysis pooling 46 studies and 5796 patients [62], the overall risk of re-bleeding was significantly higher after positive CE compared to negative CE in the Asian studies (OR: 1.8; $95 \% \mathrm{CI}, 1.1-3)$. The application of a specific therapy after a positive $C E$ index was associated with a lower re-bleeding risk in both the Western (OR 0.4; 95\% CI, 0.2-0.9) and Eastern (OR 0.4; 95\% CI, $0.2-0.7)$ populations independently of the bleeding presentation (overt vs. occult).

\subsubsection{Panel recommendations}

- For patients with anaemia and suspected obscure mid gut bleeding, $C E$ is the first-line diagnostic tool (strong recommendation, low level of evidence).

Vote result: strongly agree $66.7 \%$, agree $33.3 \%$, moderately agree $0 \%$, moderately disagree $0 \%$, disagree $0 \%$, strongly disagree $0 \%$

- DAE should be performed as the second-line intervention and in case of operative enteroscopy or bioptic sampling (strong recommendation, moderate level of evidence).

Vote result: strongly agree 60\%, agree 33.3\%, moderately agree $6.7 \%$, moderately disagree $0 \%$, disagree $0 \%$, strongly disagree $0 \%$

\section{Role of radiologic imaging of the gastrointestinal tract}

The studies evaluating the role of imaging techniques in assessing patients with anaemia have focused on computed tomography (CT) and magnetic resonance (MR). Beyond the low invasiveness, the advantages of cross-sectional imaging include the ability to examine the bowel loops throughout, with no superimposition, and the visualization of extra-luminal structures. Imaging can be performed by either enterography technique, requiring ingestion of large volumes of contrast medium, or enteroclysis, with direct administration of enteric fluid by a nasoenteric tube. The majority of studies focused on CT, which features superior temporal and spatial resolution, as compared with MR, and is widely available. Other imaging techniques are not considered; in particular, a specific role of ultrasound is not defined. The barium examination of the SB shows a low DY (3\%-17\%) [55] in detecting abnormalities in suspected SB bleeding. Some studies have demonstrated that CT enterography (CTE) is potentially useful to detect the source of GI bleeding in patients with overt but not occult bleeding. In absence of overt bleeding, imaging techniques can be considered for selected patients when conventional endoscopy and CE are inconclusive. The majority of CT studies compared the DY of radiology to that of endoscopy (such as CE and DAE) in case of obscure GI bleeding (OGIB). The DY of CE and CTE may be dependent upon the underlying causes of OGIB, thus CTE should not be considered as a first-line investigation but rather as a complementary examination to CE and it can help to determine the cause of OGIB in selected patients. Compared with cross-sectional imaging, CE is uniformly superior to detect vascular abnormalities, whereas cross-sectional imaging can identify masses and some inflammatory changes missed at CE $[63,64]$.

A single prospective study comparing CE and CTE in IDA has been published [65]. CE demonstrated to be superior to SB enteroclysis (DY 57\% vs. 12\%) and CTE (DY 78\% vs. 22\%) for patients with unexplained IDA and negative results at routine endoscopy [65]. However, the combination of the two techniques reached diagnosis in 37 out of 45 patients (82\%). Other studies have reported significantly lower results in the subset of OGIB with a DY for CTE ranging from $10 \%-15 \%$ [66,67] to $30 \%$ [68]. A few other small-scale studies (with case series including patients with both overt and obscure bleeding) have failed to demonstrate any significant difference between CE and CTE even if the DY of CE showed superior $[64,69,70]$. With regard to OGIB, DAE has a higher DY than DAE; however, a complementary role of CE, CTE and DAE has been suggested in a recent retrospective study [68] which demonstrated that the DY for DAE could be increased after obtaining a previous examination with CE or CTE, in order to assess the better enteroscopic approach.

MR enterography (MRE) is a non-invasive imaging technique with a known role in monitoring the disease activity and complications of Crohn's disease ( $\mathrm{CrD}$ ). The usefulness of MRE extends to the investigation of patients with symptoms related to the jejunoileal tract, including suspected midgut bleeding. In this setting, MRE is both alternative and complementary to CE with a prominent role when obstructive symptoms are present and in case of young age because of the prevalence of SB tumors and CrD in young patients with IDA. Moreover, the absence of ionizing radiation represents the major strength of MRE, along with rapid image acquisition and high-contrast resolution. Oral and intravenous contrast agents enable the detection of intestinal wall abnormalities. Nevertheless, some limitation in diagnostic accuracy has been measured due to the sub-optimal distension of the proximal intestinal tract. The data from the literature is limited in terms of adequate intercomparison of SB imaging techniques. MR role has been explored in prospective and retrospective studies in which the enrolment criteria consisted in IDA and/or GI symptoms suggestive of SB disease $[71,72]$. In those studies, MRE and CE showed comparable DY as to suspected mid-gut bleeding; however, a warning rose about a tendency towards limited radiologic accuracy in the proximal SB tract [72]. The head-to-head comparison of MRE and CE DY, using DBE and expert panel consensus as the reference standard, was accomplished by designing a prospective study including 38 OGIB patients [73]: CE and MRE resulted in 61\% (95\% CI, 36-81) and 21\% (95\% CI, 7-46) sensitivity and 85\% (95\% CI, 61-96) and 100\% (95\% $\mathrm{CI}, 9-100)$ specificity $v s$. the reference standard, respectively. The performance of CE strengthened its role as the first-choice option in suspected mid-gut bleeding cases and outlined the alternative and complementary usefulness of MRE in this context.

\subsection{Panel recommendation}

- For patients with anaemia, cross-sectional imaging, such as MR and $C T$, is not indicated as a first-line investigation (strong recommendation, moderate level of evidence).

Vote result: strongly agree 40\%, agree 53.3\%, moderately agree $6.7 \%$, moderately disagree $0 \%$, disagree $0 \%$, strongly disagree $0 \%$

- With IDA and suspected OGIB, CTE and MRE may be complementary to $C E$ (and DAE) for selected patients with non-diagnostic $C E$, 
contraindication to CE and/or suspected SB tumor (strong recommendation, moderate level of evidence).

Vote result: strongly agree $53.3 \%$, agree $46.7 \%$, moderately agree $0 \%$, moderately disagree $0 \%$, disagree $0 \%$, strongly disagree $0 \%$

- MRE represents a valuable diagnostic tool for IDA patients under high clinical suspicion of SB neoplasia (strong recommendation, low level of evidence).

Vote result: strongly agree $26.7 \%$, agree $73.3 \%$, moderately agree $0 \%$, moderately disagree $0 \%$, disagree $0 \%$, strongly disagree $0 \%$

\section{Specific factors}

\subsection{Helicobacter pylori}

H. pylori infection is a chronic disease that may cause IDA through different mechanisms, including blood loss, iron malabsorption, and iron consumption [74]. Occult blood loss may occur from infection-induced ulcerative or erosive lesions in the gastro-duodenal mucosa. H. pylori-associated chronic active gastritis, particularly when pangastritis or atrophy develops, causes some alterations of the gastric function, including decreased secretion of both gastric and ascorbic acids, which are essential to the intestinal absorption of dietary iron. Moreover, it has been observed that $H$. pylori induces hepcidin expression in the gastric mucosa [75]. The increased serum hepcidin levels in $H$. pylori-infected IDA patients decrease after successful $H$. pylori eradication [76]. Finally, iron sequestration and utilization by $H$. pylori itself have been reported [77].

A recent meta-analysis of cross-sectional studies overall found that $H$. pylori-infected patients are at increased risk of both IDA (OR 1.72 ; 95\% CI, 1.2-2.4) and ID (OR 1.33; 95\% CI, 1.1-1.5) as compared to those with no infection. A sub-group analysis of 4 studies on adults showed an OR of 1.7 (95\% CI, 1-2.8) for IDA in H. pylori infected patients [78].

Four meta-analyses compared Hb level modifications (Standardized Mean Difference; SMD) at 1-3 months following H. pylori eradication therapy plus iron supplementation as compared to iron supplementation alone, and showed conflicting results [78-81]. A meta-analysis (16 trials: 13 paediatric and 3 on adults, involving 956 patients) found a significant difference between the two groups (SMD: $1.48 \mathrm{~g} / \mathrm{dl} ; 95 \% \mathrm{Cl}, 1-2$ ). When taking into account the 3 studies including adults, we computed that the SMD of haemoglobin increases was $5.83 \mathrm{~g} / \mathrm{dl}$ in 103 patients receiving $H$. pylori treatment and iron as compared to $3.8 \mathrm{~g} / \mathrm{dl}$ in the 82 patients treated with iron alone (SMD: $2 \mathrm{~g} / \mathrm{dl} ; 95 \% \mathrm{Cl}, 1.5-2.5 ; P=0.05$ ) [79]. Another meta-analysis ( 8 trials: 6 paediatric and 2 on adults; 450 patients) found that the overall increase of haemoglobin levels was significantly higher in $H$. pylori eradicated patients (SMD: $1.29 \mathrm{~g} / \mathrm{dl}$; $95 \% \mathrm{CI}, 0.6-2, P=0.0002$ ) [80]. However, the sub-group analysis of the studies on adults failed to find a significant difference (SMD: $1.5 \mathrm{~g} / \mathrm{dl} ; 95 \% \mathrm{Cl}, 0.8-2.2, P=0.51 ; 128$ patients). A meta-analysis of 4 high-quality paediatric studies found that the increases in haemoglobin levels did not significantly differ between patients receiving iron and eradication therapy and those on only IRT (SMD: $4.06 \mathrm{~g} / \mathrm{dl} ; 95 \% \mathrm{CI}, 2.6-10.7 ; P=0.23$ ) [81]. Similarly, a more recent meta-analysis ( 7 studies: 6 paediatric and 1 on adults; 515 patients) has found that the haemoglobin increase did not significantly differ in the whole analysis (SMD: $0.36 \mathrm{~g} / \mathrm{dl} ; 95 \% \mathrm{CI}, 7-0.78 ; P=1$ ), as well as in the single study on adults [78]. It should be noted that all the trials on adults were confined to Asia, the quality of the studies was judged low, a significant heterogeneity among the studies emerged, and there was evidence of publication bias.
Three uncontrolled interventional studies assessed the longterm effect of $H$. pylori eradication without IRT in adult IDA patients with unexplained iron refractoriness or dependency. In an Italian study [82] on 30 patients, 18 (75\%) and 22 (91.7\%) out of $24 \mathrm{H}$. pylori-cured patients achieved IDA recovery at 6 and 12 months, respectively, at per protocol (PP) analysis, whilst no modifications occurred in the 3 patients who failed eradication. Of note, as many as $24(80 \%)$ of these patients had pangastritis [9]. Another study performed in Israel showed IDA regression 4-69 months following bacterial eradication in 11 (78.6\%) out of 14 male patients with $H$. pylori alone, as well as in further $2(25 \%)$ out 8 of patients with both H. pylori and autoimmune gastritis [83]. Finally, in a Spanish study on 84 patients (M/F: 10/74), recovery from IDA at 6 months was achieved in $80 \%$ of males, $71.4 \%$ of post-menopausal women, and $23.3 \%$ of pre-menopausal women at PP analysis [84].

\subsubsection{Panel recommendations}

- H. pylori infection needs testing in adult patients with IDA (strong recommendation, high level of evidence).

Vote result: strongly agree $33.3 \%$, agree 53.3\%, moderately agree $13.3 \%$, moderately disagree $0 \%$, disagree $0 \%$, strongly disagree $0 \%$

- Bacterial eradication may improve and accelerate IDA recovery when associated with oral iron supplementation (conditional recommendation, low level of evidence).

Vote result: strongly agree $13.3 \%$, agree $53.3 \%$, moderately agree $26.7 \%$, moderately disagree $6.7 \%$, disagree $0 \%$, strongly disagree $0 \%$

- H. pylori eradication is a therapeutic option for patients with otherwise unexplained IDA (strong recommendation, low level of evidence).

Vote result: strongly agree $13.3 \%$, agree $60 \%$, moderately agree $26.7 \%$, moderately disagree $0 \%$, disagree $0 \%$, strongly disagree $0 \%$

\subsection{Coeliac disease}

Anaemia is one of the most common presentations of $C D$, found in $12 \%-69 \%$ of adult patients, and may be the only presenting symptom [85-92]. Anaemia is mainly due to ID $(80 \%$ of cases) $[86,87]$ as a consequence of iron malabsorption [93]. On the other hand, contrasting data on the prevalence of $C D$ in patients with anaemia have been reported. A systematic review [94] evaluated 12 studies and assessed the prevalence of $\mathrm{CD}$ among patients with anaemia (especially IDA) [40,92,95-104]. These authors reported a CD frequency in IDA patients with gastrointestinal symptoms ranging from $10.3 \%$ to $15 \%[95,99,100]$. Four studies assessed the prevalence of $C D$ in asymptomatic IDA patients by serology and CD prevalence ranged from $2.3 \%$ to $5.0 \%$ [92,97,101,102]. Other three studies assessed the prevalence of CD by duodenal histology in asymptomatic IDA patients and found values ranging from 2.9\% to $6 \%[40,96,104]$. A systematic review [105] examined 13 studies and concluded that CD is demonstrable in $1.8 \%$ to $14.6 \%$ of IDA patients $[25,37,106-112]$. CD frequency is higher among patients who have not responded to oral IRT compared to responsive ones [106]. Furthermore, several studies have reported that $73 \%-100 \%$ of IDA patients diagnosed with CD were adult pre-menopausal women. The higher iron demand in adult pre-menopausal women, as a result of menstrual loss, associated to a condition of chronic iron malabsorption attributable to $\mathrm{CD}$, probably explains this higher prevalence of $C D$. However, such studies on $C D$ and anaemia were heterogeneous in design, as some included only patients with IDA whereas other studies included both folate and iron-deficiency 
patients, and used different methods to diagnose $C D$, often in selected referral populations.

In $\mathrm{CD}$ serological screening, the presence of IgA-antitransglutaminase (anti-tTG IgA) or IgG-anti-deamidated gliadin peptides (anti-DGP IgG) is considered with high suspicion of CD [113]. Other guidelines suggest anti-tTG IgA testing as the only exam [114], as its accuracy is considered sufficiently high, with sensitivity and specificity of about $95 \%$. However, as IgA deficiency occurs in $2 \%-3 \%$ of patients with CD [115], the measurement of IgA levels should be recommended, when only IgA-based CD serology is performed. In any case, intestinal biopsy and duodenal histology evaluation are essential for the diagnosis of adult $C D$ and cannot be replaced by serology. Furthermore, the prevalence of sero-negative $\mathrm{CD}$ could be much higher than commonly considered (with estimation between $6 \%$ and $22 \%$ of all diagnosed cases) [116]. Consequently, intestinal biopsies have been suggested for individuals with anaemia of unknown origin, irrespective of whether they have had serology for CD. However, HLA DQ2/DQ8 testing should be performed on the sero-negative patients who show a high clinical suspicion of $C D$ diagnosis, due to its high negative predictive value [117].

Noteworthy, iron malabsorption is not the only cause of anaemia in $\mathrm{CD}$. In some patients, nutritional fiber/calcium deficiency may also contribute to ID in CD $[118,119]$ as well as genetic factors [120]. Furthermore, other pathological mechanisms leading to anaemia in CD patients are folate and/or vitamin B12 malabsorption and deficiency. In affected individuals, low plasma folate and vitamin B12 deficiency were observed in $10 \%-81 \%$ and $5 \%-41 \%$ respectively [121-125].

Finally, persistent anaemia in CD patients on a gluten free diet needs to be carefully investigated. In this context, physicians must consider other concomitant causes of anaemia in such patients (i.e. blood loss, inflammation, nutritional deficiencies, folate and vitamin $B_{12}$ malabsorption and deficiency), development of refractory CD [126,127], concomitant H. pylori infection [78] or and ironrefractory iron deficiency anaemia (IRIDA, an autosomal recessive sideropenic anaemia) [128].

\subsubsection{Panel recommendations}

- All patients with anaemia must be serologically tested for CD (strong recommendation, high level of evidence).

Vote result: strongly agree $86.7 \%$, agree $6.7 \%$, moderately agree $6.7 \%$, moderately disagree $0 \%$, disagree $0 \%$, strongly disagree $0 \%$

- As the prevalence of sero-negative $C D$ could be high, intestinal biopsies have been suggested for individuals with anaemia of unknown origin, irrespective of whether they have had serology for $C D$ (conditional recommendation, moderate level of evidence).

Vote result: strongly agree $26.7 \%$, agree $46.7 \%$, moderately agree $20 \%$, moderately disagree $6.7 \%$, disagree $0 \%$, strongly disagree $0 \%$

\subsection{Inflammatory bowel disease}

Anaemia is the most common extra-intestinal manifestation of IBD [129], with blood loss, malabsorption, dietary restrictions, SB insufficiency being the main mechanisms [9]. Chronic disease anaemia and ID often co-exist in IBD, but the latter is prevalent $[130,131]$.

The prevalence of anaemia in IBD is varied and depends on the studied population (in/out-patient settings) and the applied criteria. A recent meta-analysis of 6 European series has showed a cumulative prevalence of $24 \%$ (95\% CI, 18-31); IDA was present in $57 \%$ of cases. Among the variables, $\mathrm{CrD}$ and active inflamma- tion were the strongest risk factors [130]. The Norwegian IBSEN inception cohort (756 patients prospectively assessed at 1, 5, 10 years) showed that the relative risk (RR) for anaemia was 2.9 (95\% CI, 1.9-4.2) and 1.7 (95\% CI, 1.1-2.4) for CrD and ulcerative colitis (UC), respectively. The prevalence of anaemia faded with the time and extent of observation; unfortunately, the data on iron status to define the type of anaemia were unavailable [132]. Furthermore, a recent retrospective study from the USA (on administrative data) on $5104 \mathrm{CrD}$ and 6249 UC cases has showed that up to one third of IBD patients present with anaemia (32.4\% and $27.6 \%$ of the $\mathrm{CrD}$ and UC cases, respectively) and most of them have IDA [131].

The guidelines to avail recommend iron therapy to all patients with IBD and IDA, with the aim of normalizing Hb levels [9]. From 2011 to date, 5 meta-analyses [133-137], a systematic review [138] comparing intravenous (i.v.) vs. oral IRT, and a meta-analysis comparing different i.v. iron formulations [137] for patients with IDA and IBD, have been published. The first meta-analysis by Lee et al. [133], which included three RCTs involving 333 patients, has showed a superiority of i.v.-administered IRT compared with oral IRT; however a high number of patients discontinued oral therapy for GI side effects (OR 6.2; 95\% CI, 2.2-17); 5 out of 203 patients stopped i.v. therapy for severe side effects (rash, thrombocytopenia, thrombophlebitis, edema). Except for one meta-analysis [135], all the other studies $[134,136,137]$ confirmed an advantage of i.v. IRT over oral IRT, with a relevant number of discontinuations during oral therapy for GI symptoms, whereas in the case of i.v. therapy the side effects were rare but clinically severe. Furthermore, a network meta-analysis [137] comparing i.v. and oral therapy and the efficacy of different i.v. iron formulations (iron carboxymaltose, iron isomaltoside, iron sucrose) found that iron carboxymaltose was superior to oral therapy $(\mathrm{OR}=1.9 ; 95 \% \mathrm{CI}, 1.1-3.2)$, without differences in safety of the different i.v. iron formulations. Interestingly, a recent study [139] has showed a shift of gut microbiota toward an unsafer composition in patients administrated with oral IRT, although the clinical implication of this finding is not yet fully understood.

\subsubsection{Panel recommendations}

- The prevalence of anaemia in IBD patients is high, thus, the presence of IBD in patients with anaemia should be carefully screened (conditional recommendation, low level of evidence).

Vote result: strongly agree 53.3\%, agree 13.3\%, moderately agree $33.3 \%$, moderately disagree $0 \%$, disagree $0 \%$, strongly disagree $0 \%$

- IRT is recommended for IDA and it is effective to use both the i.v. and oral routes. However, the i.v. route should be preferred (strong recommendation, high level of evidence).

Vote result: strongly agree $53.3 \%$, agree $40 \%$, moderately agree $6.7 \%$, moderately disagree $0 \%$, disagree $0 \%$, strongly disagree $0 \%$

\section{Approach to patients with non-iron deficiency anaemia}

Non-ID anaemia is infrequent and principally derives from vitamin $\mathrm{B}_{12}$ and/or folate deficiency. The most frequent cause of megaloblastic anaemia is autoimmune atrophic gastritis (pernicious anemia) and thus patients with macrocytic anaemia are referred to the gastroenterologist. The diagnostic work-up includes the detection of anti-parietal cell antibodies (APCA), assessment of vitamin $B_{12}$ serological levels and upper endoscopy. APCA can be found in more than $85 \%$ of patients, whilst isolate intrinsic factor antibodies presence occurs in less than $1 \%$ of patients [140]. Also pepsinogen I levels can be useful in the flowchart [141]. At upper endoscopy, multiple biopies in antrum, gastric body, fundus and duodenum should be taken, in order to perform a complete 


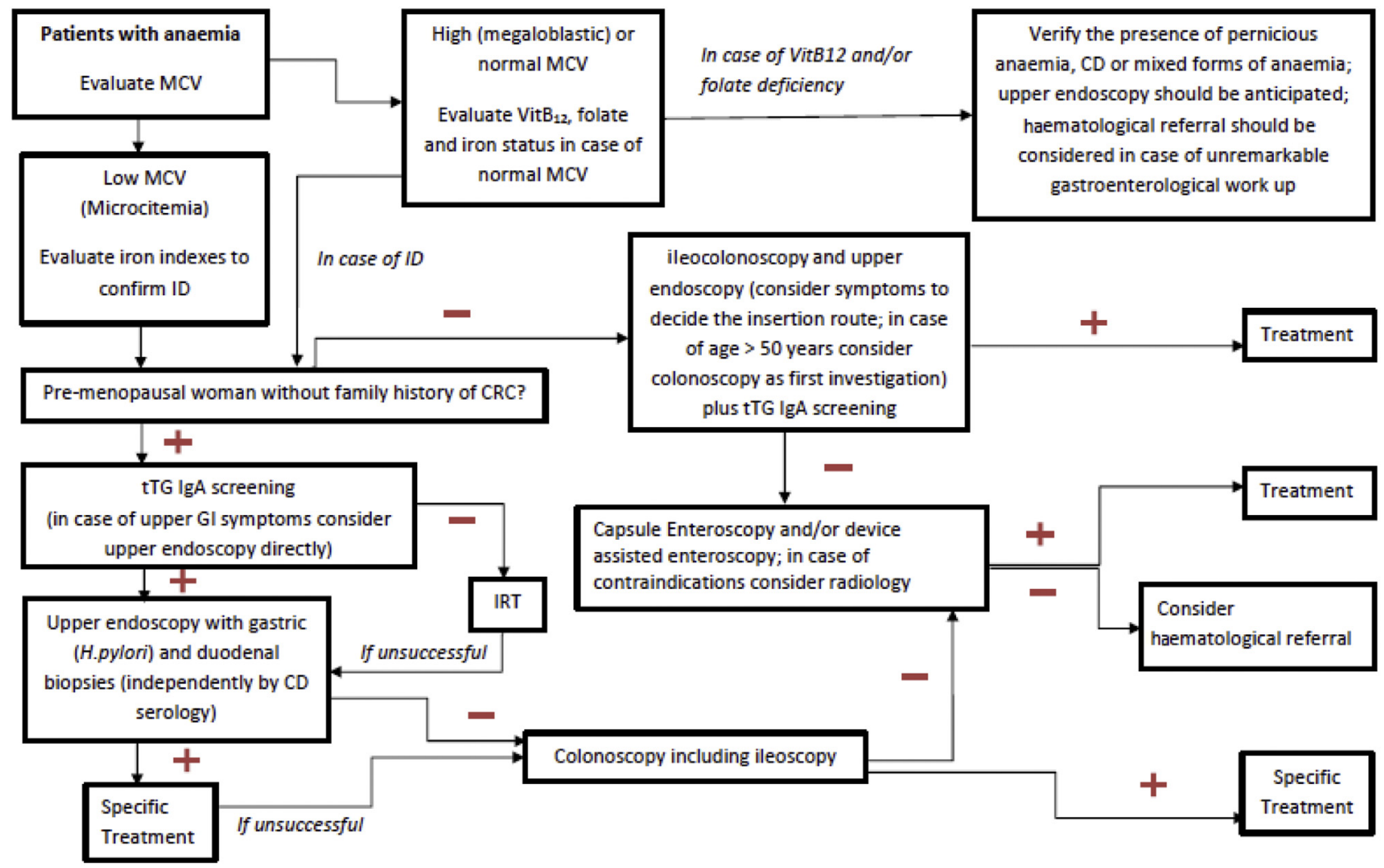

Fig. 1. Diagnostic gastroenterological flowchart for adult patients with anaemia.

assessment of the potential causes of megaloblastic anaemia. Typically, autoimmune atrophic gastritis, with or without intenstinal metaplasia, is confined in the mucosa of the gastric body and fundus, sparing the antrum. It represents a precancerous condition for both neuroendocrine tumors and gastric cancer, thus deserving endoscopic-histologic follow up every 3-4 years [142,143].

In general, the absorption of Vitamin B12 requires the normal function of the stomach, pancreas and small intestine [144]. Other causes of its deficiency are manifold: dietary low intake (as in strict vegan diet), gastrectomy, pancreatic abnormalities (chronic pancreatitis, pancreatectomy), SB disease (ileal disease, CD or CrD) terminal ileal resection or bypass, bacterial overgrowth, fish tapeworm i.e. Diphyllobothrium latum ) [145]. Among the malabsorption causes of $\mathrm{B}_{12}$ vitamin deficiency the most frequent one is pernicious anaemia [144]. In pernicious anaemia, Vitamin B12 deficiency is treated with intramuscular injection of hydroxocobalamin $1 \mathrm{mg}$ three times a week for two weeks and then three-monthly for life to prevent neurological consequences related to chronic vitamin $\mathrm{B}_{12}$ deficiency [146]. Patients with an unremarkable gastroenterological work-up should be referred to the haematologist to ruled out myelofibrosis and other haematological causes (inherited disorders, transcobalamin II deficiency, intrinsic factor deficiency, cubilin deficiency, etc.) [145].

\subsection{Panel recommendations}

- Patients with megaloblastic anaemia should investigated for autoimmune atrophic gastritis. When pernicious anaemia is diagnosed, long-life intramuscular supplementation of vitamin B12 is needed, as well as a scheduled endoscopic surveillance (strong recommendation, high level of evidence)

Vote result: strongly agree $86.7 \%$, agree $6.7 \%$, moderately agree $6.7 \%$, moderately disagree $0 \%$, disagree $0 \%$, strongly disagree $0 \%$
Table 2

Haemoglobin cut-off values for the definition of anaemia in children.

\begin{tabular}{ll}
\hline Age & Hemoglobin cut-off value $(\mathrm{g} / \mathrm{dl})$ \\
\hline $0-1$ weeks & 13.5 \\
2 months & 9 \\
$4-24$ months & 10.5 \\
$2-5$ years & 11 \\
$5-11$ years & 11.5 \\
$12-14$ years & 12 \\
\hline
\end{tabular}

- Patients with megaloblastic anaemia without pernicious anemia should be referred to the haematologist for further diagnostic workup (strong recommendation, low level of evidence)

Vote result: strongly agree $60 \%$, agree $33.3 \%$, moderately agree $6.7 \%$, moderately disagree 0\%, disagree 0\%, strongly disagree 0\%

\section{Approach to anaemic patients during childhood}

Anaemia is a diagnostic challenge during childhood as well: a systematic review has showed that IDA is a frequent condition among pre-school children all over the world [147] with a prevalence of $9.6 \%$ (95\% CI, 7.2-12.0). The normal values of Hb during childhood are reported in Table 2 [148]. Although GI diseases are well-known causes of refractory anaemia in children, the real prevalence is unclear because of the lack of systematic reviews and manuscripts investigating this specific issue. Evidence is available about the role of $H$. pylori, peptic diseases and IDA: a meta-analysis published in 2016 [78] has showed an important association (OR $2.2 ; 95 \%$ CI, 1.4-3.4) by analyzing four paediatric studies [149-152]. Following this meta-analysis, a population-based study was published [153], confirming the association between $H$. pylori and IDA (OR 1.7; 95\% CI, 1.2-2.3). Two paediatric studies [154,155] evaluated the prevalence of $C D$ in children with IDA, showing a $21.3 \%$ and 


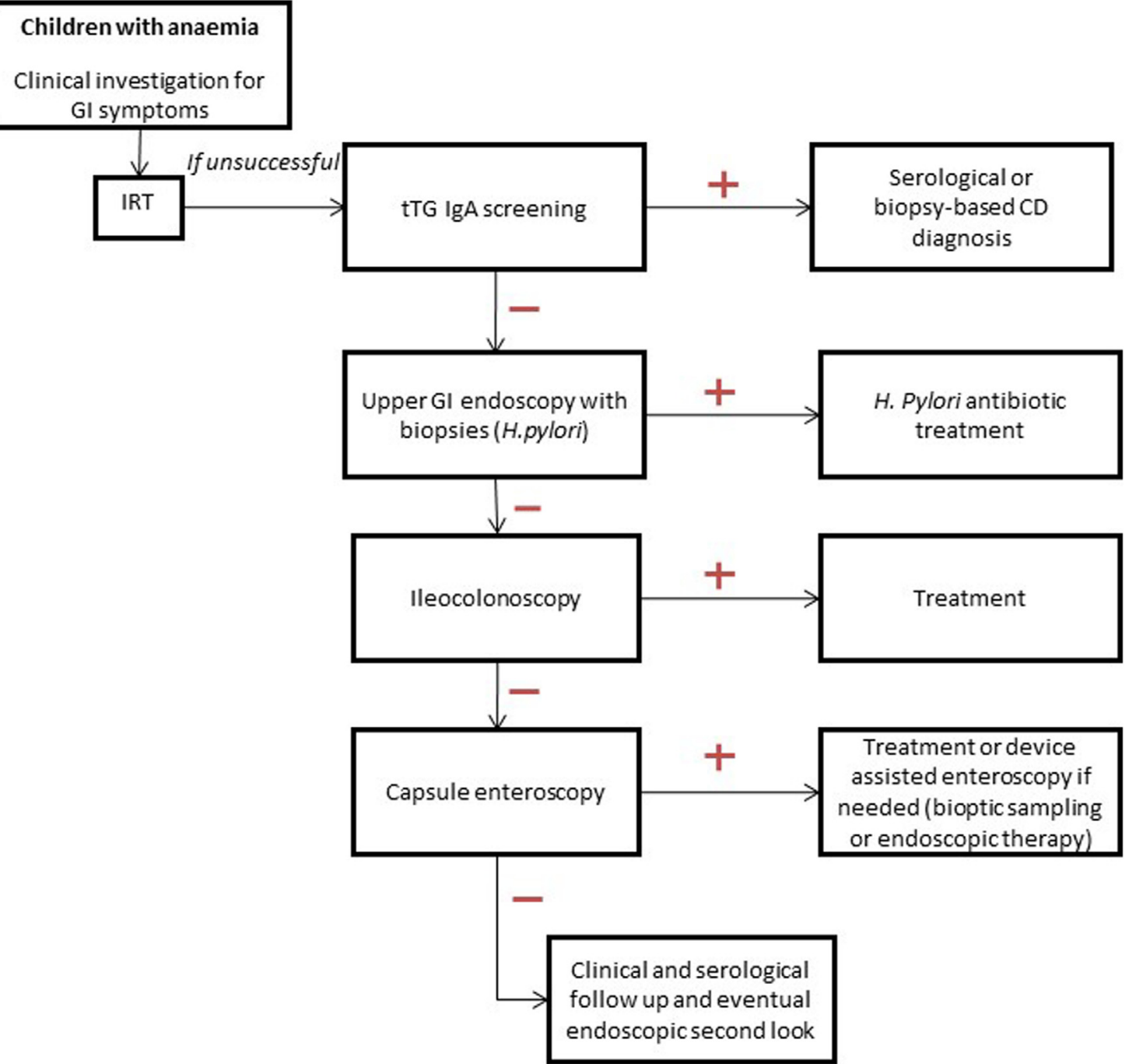

Fig. 2. Diagnostic gastroenterological flowchart for pediatric patients with anaemia.

8.4\% prevalence, respectively, and demonstrated the need for CD screening in children with IDA. Although IDA is a common complication of IBD, this issue has never been investigated as the possible alarm symptom. In a large meta-analysis, IDA was described in $24 \%$ of adults with IBD [130]. Furthermore, three studies [156-158] suggested a high prevalence of IDA at diagnosis (74\%, 30\% and 61\% respectively).

Other GI conditions to be possibly associated with chronic anaemia in children were only anecdotally reported. IDA can be caused by: gastric diseases, such as autoimmune gastritis $[159,160]$ and collagenous gastritis $[161,162]$, occult gastrointestinal bleeding due to post-surgical conditions (e.g. post anastomotic ulcerations) [163,164], vascular malformations [165,166] or blue rubber bleb nevus syndrome (BRBNS) [167,168]. Endoscopy is routinely performed to assess chronic refractory anaemia, but the evidence regarding children is scarce. Two studies $[169,170]$ addressing the role of upper gastrointestinal endoscopy, showed a DY of $84 \%$ and $43 \%$, respectively, in a small cohort of children with IDA. Lower GI endoscopy was not studied in that scenario.

OGIB and IDA are the most frequent clinical indications in children who underwent CE $[171,172]$. The DY of CE in this setting ranged from a $37 \%$ [173] to $53 \%$ [172], up to a $64 \%$ [174]. As to imaging, a study investigated the DY of MR in children with OGIB [175]: MR was performed on 13 children with a DY of $77 \%$. Two studies on DAE in children have been published with OGIB being the indication in $28 \%$ and $16 \%$, respectively, of the cases considered, with a DY of $50 \%$ and $62 \%$, respectively.

\subsection{Panel recommendations}

- Upper GI endoscopy should be considered for chronic refractory anaemia of unknown etiology in children (weak recommendation, low level of evidence).

Vote result: strongly agree $46.2 \%$, agree $73.3 \%$, moderately agree 46.2\%, moderately disagree 0\%, disagree 0\%, strongly disagree 0\%

- Lower GI endoscopy should be considered towards the diagnosis of chronic refractory anaemia (conditional recommendation, low level of evidence).

Vote result: strongly agree $46.2 \%$, agree $23.1 \%$, moderately agree $30.8 \%$, moderately disagree $0 \%$, disagree $0 \%$, strongly disagree $0 \%$

- In case of operative endoscopy CE and DAE should be performed on children with persistent anaemia and in case of inconclusive upper and lower endoscopy (conditional recommendation, low level of evidence). 
Vote result: strongly agree $38.5 \%$, agree $30.8 \%$, moderately agree $30.8 \%$, moderately disagree $0 \%$, disagree $0 \%$, strongly disagree $0 \%$

- DAE can be indicated in the diagnostic and therapeutic approaches to chronic refractory anaemia after or together with CE findings (conditional recommendation, low level of evidence).

Vote result: strongly agree $23.1 \%$, agree $46.2 \%$, moderately agree $30.8 \%$, moderately disagree $0 \%$, disagree $0 \%$, strongly disagree $0 \%$

\section{Final raccomandations}

Anaemia always poses a diagnostic challenge as numerous are the GI diseases leading to a decrease in Hb levels. A correct diagnostic approach is essential to improve a patient's prognosis and to establish correct therapeutic and follow-up processes. In view of the importance of anaemia in the clinical routine, the current lack of studies investigating this issue is bemusing. Figs. 1 and 2 provide the diagnostic roadmaps to handle adults and children with anaemia.

\section{Acknowledgments}

We thank Marcello Hinxman-Allegri for the English language revision and editing of the manuscript.

\section{Funding}

None declared.

Fondazione IRCCS Ca' Granda was funded by grants from the Italian Ministry of Health and Lombardy's Regional Government Authority (Ministero della Salute e Regione Lombardia call no. R.F.GR 2011-02348234).

\section{Appendix A. Supplementary data}

Supplementary data associated with this article can be found, in the online version, at https://doi.org/10.1016/j.dld.2019.01.022.

\section{References}

[1] Beutler E, Waalen J. The definition of anemia: what is the lower limit of normal of the blood hemoglobin concentration. Blood 2006;107:1747-50.

[2] Cappellini MD, Motta I. Anemia in clinical practice-Definition and classification: does hemoglobin change with aging. Semin Hematol 2015;52:261-9.

[3] Goddard AF, James MW, McIntyre AS, Scott BB. Gastroenterology BSo Guidelines for the management of iron deficiency anaemia. Gut 2011;60:1309-16.

[4] Buscarini E, Conte D, Cannizzaro R, Bazzoli F, De Boni M, Delle Fave G. White paper of Italian Gastroenterology: delivery of services for digestive diseases in Italy: weaknesses and strengths. Dig Liver Dis 2014;46:579-89.

[5] Freeman HJ. Iron deficiency anemia in celiac disease. World J Gastroenterol 2015;21:9233-8.

[6] Jackson CS, Strong R. Gastrointestinal angiodysplasia: diagnosis and management. Gastrointest Endosc Clin N Am 2017;27:51-62.

[7] Peyrin-Biroulet L, Lopez A, Cummings JRF, Dignass A, Detlie TE, Danese S. Review article: treating-to-target for inflammatory bowel disease-associated anaemia. Aliment Pharmacol Ther 2018;48:610-7.

[8] Bizzaro N, Antico A. Diagnosis and classification of pernicious anemia. Autoimmun Rev 2014;13:565-8.

[9] Dignass AU, Gasche C, Bettenworth D, Birgegård G, Danese S, Gisbert JP, et al. European consensus on the diagnosis and management of iron deficiency and anaemia in inflammatory bowel diseases. J Crohns Colitis 2015;9:211-22.

[10] Gasche C, Berstad A, Befrits R, Beglinger C, Dignass A, Erichsen K, et al. Guidelines on the diagnosis and management of iron deficiency and anemia in inflammatory bowel diseases. Inflamm Bowel Dis 2007;13:1545-53.

[11] Goddard AF, McIntyre AS, Scott BB. Guidelines for the management of iron deficiency anaemia British Society of Gastroenterology. Gut 2000;46(Suppl 3-4):IV1-5.

[12] Bergus GR, Randall CS, Sinift SD, Rosenthal DM. Does the structure of clinical questions affect the outcome of curbside consultations with specialty colleagues. Arch Fam Med 2000;9:541-7.

[13] Atkins D, Best D, Briss PA, Eccles M, Falck-Ytter Y, Flottorp S, et al. Grading quality of evidence and strength of recommendations. BMJ 2004;328:1490.
[14] Kassebaum NJ, Jasrasaria R, Naghavi M, Wulf SK, Johns N, Lozano R, et al A systematic analysis of global anemia burden from 1990 to 2010. Blood 2014;123:615-24.

[15] Taher AT, Weatherall DJ, Cappellini MD. Thalassaemia. Lancet 2018;391:155-67.

[16] Cappellini MD, Comin-Colet J, de Francisco A, Dignass A, Doehner W, Lam CS, et al. Iron deficiency across chronic inflammatory conditions: international expert opinion on definition, diagnosis, and management. Am J Hematol 2017;92:1068-78.

[17] Green R, Dwyre DM. Evaluation of macrocytic anemias. Semin Hematol 2015;52:279-86

[18] Winawer S, Fletcher R, Rex D, Bond J, Burt R, Ferrucci J, et al. Colorectal cancer screening and surveillance: clinical guidelines and rationale-Update based on new evidence. Gastroenterology 2003;124:544-60.

[19] Knudsen AB, Zauber AG, Rutter CM, Naber SK, Doria-Rose VP, Pabiniak C, et al. Estimation of benefits burden, and harms of colorectal cancer screening strategies: modeling study for the US preventive services task force. JAMA 2016;315:2595-609.

[20] Fisher DA, Judd L, Sanford NS. Inappropriate colorectal cancer screening: findings and implications. Am J Gastroenterol 2005;100:2526-30.

[21] Friedman A, Chan A, Chin LC, Deen A, Hammerschlag G, Lee M, et al. Use and abuse of faecal occult blood tests in an acute hospital inpatient setting. Intern Med J 2010;40:107-11.

[22] Mosadeghi S, Ren H, Catungal J, Yen I, Liu B, Wong RJ, et al. Utilization of fecal occult blood test in the acute hospital setting and its impact on clinical management and outcomes. J Postgrad Med 2016;62:91-5.

[23] Percy L, Mansour D, Fraser I. Iron deficiency and iron deficiency anaemia in women. Best Pract Res Clin Obstet Gynaecol 2017;40:55-67.

[24] Kujovich JL. Evaluation of anemia. Obstet Gynecol Clin North Am 2016;43:247-64

[25] Carter D, Maor Y, Bar-Meir S, Avidan B. Prevalence and predictive signs for gastrointestinal lesions in premenopausal women with iron deficiency anemia. Dig Dis Sci 2008;53:3138-44.

[26] Green BT, Rockey DC. Gastrointestinal endoscopic evaluation of premenopausal women with iron deficiency anemia. J Clin Gastroenterol 2004;38:104-9.

[27] Park DI, Ryu SH, Oh SJ, Yoo TW, Kim HJ, Cho YK, et al. Significance of endoscopy in asymptomatic premenopausal women with iron deficiency anemia. Dig Dis Sci 2006;51:2372-6.

[28] Ioannou GN, Rockey DC, Bryson CL, Weiss NS. Iron deficiency and gastrointestinal malignancy: a population-based cohort study. Am J Med 2002; 113:276-80.

[29] Short MW, Domagalski JE. Iron deficiency anemia: evaluation and management. Am Fam Physician 2013;87:98-104.

[30] Liu K, Kaffes AJ. Iron deficiency anaemia: a review of diagnosis, investigation and management. Eur J Gastroenterol Hepatol 2012;24:109-16.

[31] Castells A, Marzo M, Bellas B, Amador FJ, Lanas A, Mascort JJ, et al. [Clinical guidelines for the prevention of colorectal cancer]. Gastroenterol Hepatol 2004;27:573-634.

[32] Rockey DC, Cello JP. Evaluation of the gastrointestinal tract in patients with iron-deficiency anemia. N Engl J Med 1993;329:1691-5.

[33] Hardwick RH, Armstrong CP. Synchronous upper and lower gastrointestinal endoscopy is an effective method of investigating iron-deficiency anaemia. Br J Surg 1997;84:1725-8.

[34] Gordon SR, Smith RE, Power GC. The role of endoscopy in the evaluation of iron deficiency anemia in patients over the age of 50. Am J Gastroenterol 1994;89:1963-7

[35] Tee HP, Kaffes AJ. Non-small-bowel lesions encountered during doubleballoon enteroscopy performed for obscure gastrointestinal bleeding. World J Gastroenterol 2010;16:1885-9.

[36] Stray N, Weberg R. A prospective study of same day bi-directional endoscopy in the evaluation of patients with occult gastrointestinal bleeding. Scand Gastroenterol 2006;41:844-50.

[37] Hershko C, Hoffbrand AV, Keret D, Souroujon M, Maschler I, Monselise Y, et al. Role of autoimmune gastritis Helicobacter pylori and celiac disease in refractory or unexplained iron deficiency anemia. Haematologica 2005;90: 585-95.

[38] Dickey W, McMillan SA, McCrum EE, Evans AE. Association between serum levels of total IgA and IgA class endomysial and antigliadin antibodies: implications for coeliac disease screening. Eur J Gastroenterol Hepatol 1997;9:559-62.

[39] Capurso G, Baccini F, Osborn J, Panzuto F, Di Giulio E, Delle Fave G, et al. Can patient characteristics predict the outcome of endoscopic evaluation of iron deficiency anemia: a multiple logistic regression analysis. Gastrointest Endosc 2004;59:766-71.

[40] McIntyre AS, Long RG. Prospective survey of investigations in outpatients referred with iron deficiency anaemia. Gut 1993;34:1102-7.

[41] Rockey DC. Occult gastrointestinal bleeding. N Engl J Med 1999;341:38-46.

[42] Powell N, McNair A. Gastrointestinal evaluation of anaemic patients without evidence of iron deficiency. Eur J Gastroenterol Hepatol 2008;20:1094-100.

[43] Sawhney MS, Lipato T, Nelson DB, Lederle FA, Rector TS, Bond JH. Should patients with anemia and low normal or normal serum ferritin undergo colonoscopy? Am J Gastroenterol 2007;102:82-8.

[44] Wang SA, Fadare O, Nagar A, Shafi NQ, Rose MG. Gastrointestinal endoscopic findings in men with unexplained anemia and low normal ferritin values. Am J Hematol 2006;81:324-7. 
[45] Moses PL, Smith RE. Endoscopic evaluation of iron deficiency anemia. A guide to diagnostic strategy in older patients. Postgrad Med 1995;98:213-6, 9, 22-4 passim.

[46] Zuckerman GR, Prakash C, Askin MP, Lewis BS. AGA technical review on the evaluation and management of occult and obscure gastrointestinal bleeding. Gastroenterology 2000;118:201-21.

[47] Peytremann-Bridevaux I, Arditi C, Froehlich F, O'Malley J, Fairclough P, Le Moine $\mathrm{O}$, et al. Appropriateness of colonoscopy in europe (EPAGE II). Irondeficiency anemia and hematochezia. Endoscopy 2009;41:227-33.

[48] Carter D, Levi G, Tzur D, Novis B, Avidan B. Prevalence and predictive factors for gastrointestinal pathology in young men evaluated for iron deficiency anemia. Dig Dis Sci 2013;58:1299-305.

[49] Rockey DC. Occult and obscure gastrointestinal bleeding: causes and clinical management. Nat Rev Gastroenterol Hepatol 2010;7:265-79.

[50] Landy J, Macfarlane B. Synchronous bidirectional endoscopy for iron deficiency anaemia: is it appropriate for patients under 50? Postgrad Med J 2010;86:338-40.

[51] Kim NH, Park JH, Park DI, Sohn CI, Choi K, Jung YS. Should asymptomatic young men with iron deficiency anemia necessarily undergo endoscopy? Korean J Intern Med 2018.

[52] Saks K, Enestvedt BK, Holub JL, Lieberman D. Colonoscopy identifies increased prevalence of large polyps or tumors in patients 40-49 years old with hematochezia vs other gastrointestinal indications. Clin Gastroenterol Hepatol 2016;14:843-9.

[53] Pennazio M, Spada C, Eliakim R, Keuchel M, May A, Mulder CJ, et al. Small-bowel capsule endoscopy and device-assisted enteroscopy for diagnosis and treatment of small-bowel disorders: european Society of Gastrointestinal Endoscopy (ESGE) Clinical Guideline. Endoscopy 2015;47: 352-76.

[54] Rondonotti E, Spada C, Adler S, May A, Despott EJ, Koulaouzidis A, et al. Smallbowel capsule endoscopy and device-assisted enteroscopy for diagnosis and treatment of small-bowel disorders: european Society of Gastrointestinal Endoscopy (ESGE) Technical Review. Endoscopy 2018;50:423-46.

[55] Gerson LB, Fidler JL, Cave DR, Leighton JA. ACG clinical guideline: diagnosis and management of small bowel bleeding. Am J Gastroenterol 2015;110:1265-87, quiz 88.

[56] Gurudu SR, Bruining DH, Acosta RD, Eloubeidi MA, Faulx AL, Khashab MA, et al. The role of endoscopy in the management of suspected small-bowel bleeding. Gastrointest Endosc 2017:85:22-31.

[57] Enns RA, Hookey L, Armstrong D, Bernstein CN, Heitman SJ, Teshima C, et al. Clinical practice guidelines for the use of video capsule endoscopy. Gastroenterology 2017;152:497-514.

[58] Koulaouzidis A, Rondonotti E, Giannakou A, Plevris JN. Diagnostic yield of small-bowel capsule endoscopy in patients with iron-deficiency anemia: a systematic review. Gastrointest Endosc 2012;76:983-92.

[59] Yung DE, Rondonotti E, Giannakou A, Avni T, Rosa B, Toth E, et al. Capsule endoscopy in young patients with iron deficiency anaemia and negative bidirectional gastrointestinal endoscopy. United European Gastroenterol J 2017:5:974-81

[60] Teshima CW, Kuipers EJ, van Zanten SV, Mensink PB. Double balloon enteroscopy and capsule endoscopy for obscure gastrointestinal bleeding: an updated meta-analysis. J Gastroenterol Hepatol 2011;26:796-801.

[61] Gerson L, Kamal A. Cost-effectiveness analysis of management strategies for obscure GI bleeding. Gastrointest Endosc 2008;68:920-36.

[62] Tziatzios G, Gkolfakis P, Hassan C, Toth E, Zullo A, Koulaouzidis A, et al. Meta-analysis shows similar re-bleeding rates among Western and Eastern populations after index video capsule endoscopy. Dig Liver Dis 2018;50:226-39.

[63] Huprich JE, Fletcher JG, Fidler JL, Alexander JA, Guimarães LS, Siddiki HA, et al. Prospective blinded comparison of wireless capsule endoscopy and multiphase CT enterography in obscure gastrointestinal bleeding. Radiology 2011;260:744-51

[64] Khalife S, Soyer P, Alatawi A, Vahedi K, Hamzi L, Dray X, et al. Obscure gastrointestinal bleeding: preliminary comparison of 64-section CT enteroclysis with video capsule endoscopy. Eur Radiol 2011;21:79-86.

[65] Milano A, Balatsinou C, Filippone A, Caldarella MP, Laterza F, Lapenna D, et al. A prospective evaluation of iron deficiency anemia in the GI endoscopy setting: role of standard endoscopy, videocapsule endoscopy, and CT-enteroclysis. Gastrointest Endosc 2011;73:1002-8.

[66] Lee SS, Oh TS, Kim HJ, Chung JW, Park SH, Kim AY, et al. Obscure gastrointestinal bleeding: diagnostic performance of multidetector CT enterography. Radiology 2011;259:739-48.

[67] Jain TP, Gulati MS, Makharia GK, Bandhu S, Garg PKCT. enteroclysis in the diagnosis of obscure gastrointestinal bleeding: initial results. Clin Radiol 2007;62:660-7

[68] Law R, Varayil JE, WongKeeSong LM, Fidler J, Fletcher JG, Barlow J, et al. Assessment of multi-modality evaluations of obscure gastrointestinal bleeding. World J Gastroenterol 2017;23:614-21.

[69] He B, Gong S, Hu C, Fan J, Qian J, Huang S, et al. Obscure gastrointestinal bleeding: diagnostic performance of 64-section multiphase CT enterography and CT angiography compared with capsule endoscopy. Br J Radiol 2014;87:20140229.

[70] Gong PY, Li JX, Huang LY, Zhang LM, Xie HZ, Sui YB. Prospective blinded comparison of computed tomographic enterography and small bowel endoscopy in obscure gastrointestinal bleeding. Hepatogastroenterology 2014;61:984-8.
[71] Cengic I, Tureli D, Aydin H, Bugdayci O, Imeryuz N, Tuney D. Magnetic resonance enterography in refractory iron deficiency anemia: a pictorial overview. World J Gastroenterol 2014;20:14004-9.

[72] Böcker U, Dinter D, Litterer C, Hummel F, Knebel P, Franke A, et al. Comparison of magnetic resonance imaging and video capsule enteroscopy in diagnosing small-bowel pathology: localization-dependent diagnostic yield. Scand J Gastroenterol 2010;45:490-500.

[73] Wiarda BM, Heine DG, Mensink P, Stolk M, Dees J, Hazenberg HJ, et al Comparison of magnetic resonance enteroclysis and capsule endoscopy with balloon-assisted enteroscopy in patients with obscure gastrointestinal bleeding. Endoscopy 2012;44:668-73.

[74] Stein J, Connor S, Virgin G, Ong DE, Pereyra L. Anemia and iron deficiency in gastrointestinal and liver conditions. World J Gastroenterol 2016;22:7908-25.

[75] Schwarz P, Kübler JA, Strnad P, Müller K, Barth TF, Gerloff A, et al. Hepcidin is localised in gastric parietal cells, regulates acid secretion and is induced by Helicobacter pylori infection. Gut 2012;61:193-201.

[76] Sapmaz F, Bassyiğit S, Kalkan I, Kısa Ü, Kavak EE, Güliter S. The impact of Helicobacter pylori eradication on serum hepcidin-25 level and iron parameters in patients with iron deficiency anemia. Wien Klin Wochenschr 2016;128:335-40.

[77] He X, Liao X, Li H, Xia W, Sun H. Bismuth-Induced inactivation of ferric uptake regulator from helicobacter pylori. Inorg Chem 2017;56:15041-8.

[78] Hudak L, Jaraisy A, Haj S, Muhsen K. An updated systematic review and metaanalysis on the association between Helicobacter pylori infection and iron deficiency anemia. Helicobacter 2017;22.

[79] Yuan W, Yumin Li, Kehu Yang, Bin Ma, Quanlin Guan, Wang D, et al. Iron deficiency anemia in Helicobacter pylori infection: meta-analysis of randomized controlled trials. Scand J Gastroenterol 2010;45:665-76.

[80] Huang X, Qu X, Yan W, Huang Y, Cai M, Hu B, et al. Iron deficiency anaemia can be improved after eradication of Helicobacter pylori. Postgrad Med 2010:86:272-8

[81] Qu XH, Huang XL, Xiong P, Zhu CY, Huang YL, Lu LG, et al. Does Helicobacter pylori infection play a role in iron deficiency anemia? A meta-analysis. World J Gastroenterol 2010;16:886-96.

[82] Annibale B, Marignani M, Monarca B, Antonelli G, Marcheggiano A, Martino G, et al. Reversal of iron deficiency anemia after Helicobacter pylori eradication in patients with asymptomatic gastritis. Ann Intern Med 1999;131:668-72.

[83] Hershko C, Ianculovich M, Souroujon M. A hematologist's view of unexplained iron deficiency anemia in males: impact of Helicobacter pylori eradication. Blood Cells Mol Dis 2007;38:45-53.

[84] Monzón H, Forné M, Esteve M, Rosinach M, Loras C, Espinós JC, et al. Helicobacter pylori infection as a cause of iron deficiency anaemia of unknown origin. World J Gastroenterol 2013;19:4166-71.

[85] Unsworth DJ, Lock FJ, Harvey RF. Iron-deficiency anaemia in premenopausal women. Lancet 1999:353:1100.

[86] Volta U, Caio G, Stanghellini V, De Giorgio R. The changing clinical profile of celiac disease: a 15-year experience (1998-2012) in an Italian referral center. BMC Gastroenterol 2014;14:194.

[87] Wierdsma NJ, van Bokhorst-de van der Schueren MA, Berkenpas M, Mulder CJ, van Bodegraven AA. Vitamin and mineral deficiencies are highly prevalent in newly diagnosed celiac disease patients. Nutrients 2013;5:3975-92.

[88] Bottaro G, Cataldo F, Rotolo N, Spina M, Corazza GR. The clinical pattern of subclinical/silent celiac disease: an analysis on 1026 consecutive cases. Am J Gastroenterol 1999;94:691-6.

[89] Lo W, Sano K, Lebwohl B, Diamond B, Green PH. Changing presentation of adult celiac disease. Dig Dis Sci 2003;48:395-8.

[90] Kolho KL, Färkkilä MA, Savilahti E. Undiagnosed coeliac disease is common in Finnish adults. Scand J Gastroenterol 1998;33:1280-3

[91] Hin H, Bird G, Fisher P, Mahy N, Jewell D. Coeliac disease in primary care: case finding study. BMJ 1999;318:164-7.

[92] Howard MR, Turnbull AJ, Morley P, Hollier P, Webb R, Clarke A. A prospective study of the prevalence of undiagnosed coeliac disease in laboratory defined iron and folate deficiency. J Clin Pathol 2002;55:754-7.

[93] Çekın AH, Çekın Y, Sezer C. Celiac disease prevalence in patients with iron deficiency anemia. Turk J Gastroenterol 2012;23:490-5.

[94] Dubé C, Rostom A, Sy R, Cranney A, Saloojee N, Garritty C, et al. The prevalence of celiac disease in average-risk and at-risk Western European populations: a systematic review. Gastroenterology 2005;128:S57-67.

[95] Ackerman Z, Eliakim R, Stalnikowicz R, Rachmilewitz D. Role of small bowel biopsy in the endoscopic evaluation of adults with iron deficiency anemia. Am J Gastroenterol 1996;91:2099-102.

[96] Annibale B, Capurso G, Chistolini A, D’Ambra G, DiGiulio E, Monarca B, et al Gastrointestinal causes of refractory iron deficiency anemia in patients without gastrointestinal symptoms. Am J Med 2001;111:439-45.

[97] Corazza GR, Valentini RA, Andreani ML, D’Anchino M, Leva MT, Ginaldi L, et al Subclinical coeliac disease is a frequent cause of iron-deficiency anaemia. Scand J Gastroenterol 1995;30:153-6.

[98] Dickey W, Kenny BD, McMillan SA, Porter KG, McConnell JB. Gastric as well as duodenal biopsies may be useful in the investigation of iron deficiency anaemia. Scand J Gastroenterol 1997;32:469-72.

[99] Kepczyk T, Kadakia SC. Prospective evaluation of gastrointestinal tract in patients with iron-deficiency anemia. Dig Dis Sci 1995;40:1283-9.

[100] Oxentenko AS, Grisolano SW, Murray JA, Burgart LJ, Dierkhising RA, Alexander JA. The insensitivity of endoscopic markers in celiac disease. Am J Gastroenterol 2002;97:933-8. 
[101] Ransford RA, Hayes M, Palmer M, Hall MJ. A controlled, prospective screening study of celiac disease presenting as iron deficiency anemia. J Clin Gastroenterol 2002;35:228-33.

[102] Unsworth DJ, Lock RJ, Harvey RF. Improving the diagnosis of coeliac disease in anaemic women. Br J Haematol 2000;111:898-901.

[103] Annibale B, Lahner E, Chistolini A, Gailucci C, Di Giulio E, Capurso G, et al. Endoscopic evaluation of the upper gastrointestinal tract is worthwhile in premenopausal women with iron-deficiency anaemia irrespective of menstrual flow. Scand J Gastroenterol 2003;38:239-45.

[104] van Mook WN, Bourass-Bremers IH, Bos LP, Verhoeven HM, Engels LG. The outcome of esophagogastroduodenoscopy (EGD) in asymptomatic outpatients with iron deficiency anemia after a negative colonoscopy. Eur J Intern Med 2001;12:122-6.

[105] Fernández-Bañares F, Monzón H, Forné M. A short review of malabsorption and anemia. World J Gastroenterol 2009;15:4644-52.

[106] Carroccio A, Iannitto E, Cavataio F, Montalto G, Tumminello M, Campagna P, et al. Sideropenic anemia and celiac disease: one study, two points of view. Dig Dis Sci 1998;43:673-8.

[107] Haslam N, Lock RJ, Unsworth DJ. Coeliac disease, anaemia and pregnancy. Clin Lab 2001;47:467-9.

[108] Annibale B, Severi C, Chistolini A, Antonelli G, Lahner E, Marcheggiano A, et al. Efficacy of gluten-free diet alone on recovery from iron deficiency anemia in adult celiac patients. Am J Gastroenterol 2001;96:132-7.

[109] Grisolano SW, Oxentenko AS, Murray JA, Burgart LJ, Dierkhising RA, Alexander JA. The usefulness of routine small bowel biopsies in evaluation of iron deficiency anemia. J Clin Gastroenterol 2004;38:756-60.

[110] Mandal AK, Mehdi I, Munshi SK, Lo TC. Value of routine duodenal biopsy in diagnosing coeliac disease in patients with iron deficiency anaemia. Postgrad Med J 2004;80:475-7.

[111] Kalayci AG, Kanber Y, Birinci A, Yildiz L, Albayrak D. The prevalence of coeliac disease as detected by screening in children with iron deficiency anaemia. Acta Paediatr 2005;94:678-81.

[112] Zamani F, Mohamadnejad M, Shakeri R, Amiri A, Najafi S, Alimohamadi SM, et al. Gluten sensitive enteropathy in patients with iron deficiency anemia of unknown origin. World J Gastroenterol 2008;14:7381-5

[113] Ludvigsson JF, Bai JC, Biagi F, Card TR, Ciacci C, Ciclitira PJ, et al. Diagnosis and management of adult coeliac disease: guidelines from the British Society of Gastroenterology. Gut 2014;63:1210-28.

[114] Rubio-Tapia A, Hill ID, Kelly CP, Calderwood AH, Murray JA. ACG clinical guidelines: diagnosis and management of celiac disease. Am J Gastroenterol 2013;108:656-76, quiz 77.

[115] McGowan KE, Lyon ME, Butzner JD. Celiac disease and IgA deficiency: complications of serological testing approaches encountered in the clinic. Clin Chem 2008;54:1203-9.

[116] Volta U, Caio G, Boschetti E, Giancola F, Rhoden KJ, Ruggeri E, et al. Seronegative celiac disease: shedding light on an obscure clinical entity. Dig Liver Dis 2016;48:1018-22.

[117] Rubio-Tapia A, Hill ID, Kelly CP, Calderwood AH, Murray JA. Gastroenterology ACo ACG clinical guidelines: diagnosis and management of celiac disease. Am J Gastroenterol 2013;108:656-76, quiz 77

[118] Aspuru K, Villa C, Bermejo F, Herrero P, López SG. Optimal management of iron deficiency anemia due to poor dietary intake. Int J Gen Med 2011;4:741-50.

[119] Martin J, Geisel T, Maresch C, Krieger K, Stein J. Inadequate nutrient intake in patients with celiac disease: results from a German dietary survey. Digestion 2013;87:240-6.

[120] Elli L, Poggiali E, Tomba C, Andreozzi F, Nava I, Bardella MT, et al. Does TMPRSS6 RS855791 polymorphism contribute to iron deficiency in treated celiac disease? Am J Gastroenterol 2015;110:200-2.

[121] Bodé S, Gudmand-Høyer E. Symptoms and haematologic features in consecutive adult coeliac patients. Scand J Gastroenterol 1996;31:54-60.

[122] Pittschieler K. Folic acid concentration in the serum and erythrocytes of patients with celiac disease. Padiatr Padol 1986;21:363-6.

[123] Dahele A, Ghosh S. Vitamin B12 deficiency in untreated celiac disease. Am J Gastroenterol 2001;96:745-50.

[124] Dickey W. Low serum vitamin B12 is common in coeliac disease and is not due to autoimmune gastritis. Eur J Gastroenterol Hepatol 2002;14:425-7.

[125] Harper JW, Holleran SF, Ramakrishnan R, Bhagat G, Green PH. Anemia in celiac disease is multifactorial in etiology. Am J Hematol 2007;82:996-1000.

[126] Ryan BM, Kelleher D. Refractory celiac disease. Gastroenterology 2000;119:243-51.

[127] Elli L, Casazza G, Locatelli M, Branchi F, Ferretti F, Conte D, et al. Use of enteroscopy for the detection of malignant and premalignant lesions of the small bowel in complicated celiac disease: a meta-analysis. Gastrointest Endosc 2017:86:264-73, e1.

[128] Heeney MM, Finberg KE. Iron-refractory iron deficiency anemia (IRIDA). Hematol Oncol Clin North Am 2014;28:637-52.

[129] Gasche C, Lomer MC, Cavill I, Weiss G. Iron anaemia, and inflammatory bowel diseases. Gut 2004;53:1190-7.

[130] Filmann N, Rey J, Schneeweiss S, Ardizzone S, Bager P, Bergamaschi G, et al. Prevalence of anemia in inflammatory bowel diseases in european countries: a systematic review and individual patient data meta-analysis. Inflamm Bowel Dis 2014;20:936-45.

[131] Akhuemonkhan E, Parian A, Miller K, Hanauer S, Hutfless S. Prevalence and screening for anaemia in mild to moderate Crohn's disease and ulcerative colitis in the United States, 2010-2014. BMJ Open Gastroenterol 2017;4:e000155.
[132] Høivik ML, Reinisch W, Cvancarova M, Moum B. Anaemia in inflammatory bowel disease: a population-based 10-year follow-up. Aliment Pharmacol Ther 2014;39:69-76.

[133] Lee TW, Kolber MR, Fedorak RN, van Zanten SV. Iron replacement therapy in inflammatory bowel disease patients with iron deficiency anemia: a systematic review and meta-analysis. J Crohns Colitis 2012;6:267-75.

[134] Avni T, Bieber A, Steinmetz T, Leibovici L, Gafter-Gvili A. Treatment of anemia in inflammatory bowel disease-systematic review and meta-analysis. PLoS One 2013;8:e75540.

[135] Abhyankar A, Moss AC. Iron replacement in patients with inflammatory bowel disease: a systematic review and meta-analysis. Inflamm Bowel Dis 2015;21:1976-81.

[136] Bonovas S, Fiorino G, Allocca M, Lytras T, Nikolopoulos GK, Peyrin-Biroulet L, et al. Biologic therapies and risk of infection and malignancy in patients with inflammatory bowel disease: a systematic review and network meta-analysis. Clin Gastroenterol Hepatol 2016;14:1385-97, e10.

[137] Aksan A, Işık H, Radeke HH, Dignass A, Stein J. Systematic review with network meta-analysis: comparative efficacy and tolerability of different intravenous iron formulations for the treatment of iron deficiency anaemia in patients with inflammatory bowel disease. Aliment Pharmacol Ther 2017;45:1303-18

[138] Nielsen OH, Ainsworth M, Coskun M, Weiss G. Management of iron-Deficiency anemia in inflammatory bowel disease: a systematic review. Medicine (Baltimore) 2015;94:e963.

[139] Lee T, Clavel T, Smirnov K, Schmidt A, Lagkouvardos I, Walker A, et al. Oral versus intravenous iron replacement therapy distinctly alters the gut microbiota and metabolome in patients with IBD. Gut 2017;66:863-71.

[140] Khan S, Del-Duca C, Fenton E, Holding S, Hirst J, Doré PC, et al. Limited value of testing for intrinsic factor antibodies with negative gastric parietal cell antibodies in pernicious anaemia. J Clin Pathol 2009;62:439-41.

[141] De Re V, Orzes E, Canzonieri V, Maiero S, Fornasarig M, Alessandrini L, et al Pepsinogens to distinguish patients with gastric intestinal metaplasia and helicobacter pylori infection among populations at risk for gastric cancer. Clin Transl Gastroenterol 2016;7:e183.

[142] Dinis-Ribeiro M, Areia M, de Vries AC, Marcos-Pinto R, Monteiro-Soares M, O'Connor A, et al. Management of precancerous conditions and lesions in the stomach (MAPS): guideline from the european society of gastrointestinal endoscopy (ESGE), european helicobacter study group (EHSG) european society of pathology (ESP), and the sociedade portuguesa de endoscopia digestiva (SPED). Endoscopy 2012;44:74-94.

[143] Lahner E, Hassan C, Esposito G, Carabotti M, Zullo A, Dinis-Ribeiro M, et al. Cost of detecting gastric neoplasia by surveillance endoscopy in atrophic gastritis in Italy: a low risk country. Dig Liver Dis 2017:49:291-6.

[144] Lahner E, Annibale B. Pernicious anemia: new insights from a gastroenterological point of view. World J Gastroenterol 2009;15:5121-8.

[145] Shipton MJ, Thachil J. Vitamin B12 deficiency - a 21 st century perspective. Clin Med (Lond) 2015;15:145-50

[146] Minalyan A, Benhammou JN, Artashesyan A, Lewis MS, Pisegna JR. Autoimmune atrophic gastritis: current perspectives. Clin Exp Gastroenterol 2017;10:19-27.

[147] Petry N, Olofin I, Hurrell RF, Boy E, Wirth JP, Moursi M, et al. The proportion of anemia associated with iron deficiency in low medium, and high human development index countries: a systematic analysis of national surveys. Nutrients 2016;8

[148] Domellöf M, Braegger C, Campoy C, Colomb V, Decsi T, Fewtrell M, et al. Iron requirements of infants and toddlers. J Pediatr Gastroenterol Nutr 2014;58:119-29.

[149] Baggett HC, Parkinson AJ, Muth PT, Gold BD, Gessner BD. Endemic iron deficiency associated with Helicobacter pylori infection among school-aged children in Alaska. Pediatrics 2006;117:e396-404.

[150] Cherian S, Forbes D, Sanfilippo F, Cook A, Burgner D. The epidemiology of Helicobacter pylori infection in African refugee children resettled in Australia. Med J Aust 2008;189:438-41.

[151] Choe YH, Kwon YS, Jung MK, Kang SK, Hwang TS, Hong YC. Helicobacter pyloriassociated iron-deficiency anemia in adolescent female athletes. J Pediatr 2001;139:100-4

[152] Xia W, Zhang X, Wang J, Sun C, Wu L. Survey of anaemia and Helicobacter pylori infection in adolescent girls in Suihua, China and enhancement of iron intervention effects by H. pylori eradication. Br J Nutr 2012;108:357-62.

[153] Taye B, Enquselassie F, Tsegaye A, Amberbir A, Medhin G, Fogarty A, et al. Effect of early and current Helicobacter pylori infection on the risk of anaemia in 6.5-year-old Ethiopian children. BMC Infect Dis 2015;15:270.

[154] Ertekin V, Tozun MS, Küçük N. The prevalence of celiac disease in children with iron-deficiency anemia. Turk J Gastroenterol 2013;24:334-8.

[155] Karaman K, Akbayram S, Kar S, Demirören K. Prevalence of celiac disease in children with iron deficiency anemia in van lake region of Turkey. J Pediatr Hematol Oncol 2016:38:143-6.

[156] Wiskin AE, Fleming BJ, Wootton SA, Beattie RM. Anaemia and iron deficiency in children with inflammatory bowel disease. J Crohns Colitis 2012;6:687-91.

[157] Sjöberg D, Holmström T, Larsson M, Nielsen AL, Holmquist L, Rönnblom A. Anemia in a population-based IBD cohort (ICURE): still high prevalence after 1öyear, especially among pediatric patients. Inflamm Bowel Dis 2014;20:2266-70.

[158] Gonçalves C, Oliveira ME, Palha AM, Ferrão A, Morais A, Lopes AI. Autoimmune gastritis presenting as iron deficiency anemia in childhood. World J Gastroenterol 2014;20:15780-6. 
G Model

YDLD-3996; No. of Pages 13

L. Eli, L. Norsa, A. Zullo, et al. / Digestive and Liver Disease $x x x$ (2019) $x x x-x x x$

13

[159] Miguel N, Costa E, Santalha M, Lima R, Vizcaino JR, Pereira F, et al. Refractory iron-deficiency anemia and autoimmune atrophic gastritis in pediatric age group: analysis of 8 clinical cases. J Pediatr Hematol Oncol 2014;36:134-9.

[160] Pogoriler J, Kain D, Goldsmith JD. Pediatric non-Helicobacter pylori atrophic gastritis: a case series. Am J Surg Pathol 2015;39:786-92.

[161] Hejaz NM, Septer SS, Degaetano J, Attard TM. Clinical outcome of pediatric collagenous gastritis: case series and review of literature. World J Gastroenterol 2013;19:1478-84.

[162] Ma C, Park JY, Montgomery EA, Arnold CA, McDonald OG, Lu TC, et al. A comparative clinicopathologic study of collagenous gastritis in children and adults: the same disorder with associated immune-mediated diseases. Am J Surg Pathol 2015;39:802-12.

[163] Charbit-Henrion F, Charcot C, Ruemmele F, Talbotec C, Morali A, Goulet O, et al. Anastomotic ulcerations after intestinal resection in infancy. J Pediatr Gastroenterol Nutr 2014;59:531-6.

[164] Gibbons TE, Cartel HB, Vaughan JF, Dassinger MS. Staple line ulcers: a cause of chronic GI bleeding following STEP procedure. J Pediatr Surg 2013;48:E1-3.

[165] Kalmar PI, Petnehazy T, Wießpeiner U, Beer M, Haver AC, Till H, et al. Large, segmental, circular vascular malformation of the small intestine (in a female toddler with hematochezia): unusual presentation in a child. BMC Pediatr 2014; $14: 55$

[166] Kim SH, Che YH, Kim HY. Vascular malformations of the small intestine manifesting as chronic anemia: two pediatric cases managed by single-site umbilical laparoscopic surgery. Int J Surg Case Rep 2017;31:233-6.

[167] Agnes M, Cipolletta L, Bianco MA, Quitadamo P, Miele E, Staiano A. Blue rubber bleb nevus syndrome. Acta Paediatr 2010;99:632-5.
[168] Srinivasan P, Brandler M, D’Souza A, Milkman P, Moreau H. Allergic enterocolitis presenting as recurrent necrotizing enterocolitis in preterm neonates. J Perinatol 2010;30:431-3

[169] Faye SB, Aref MI, Fathy HM, Abd El Dayem SM, Emara NA, Maklof A, et al. Prevalence of celiac disease, Helicobacter pylori and gastroesophageal reflux in patients with refractory iron deficiency anemia. J Trop Pediatr 2008;54:43-53.

[170] Gulden H, Kasirga E, Yildirim SA, Kader S, Shin G, Ayhan S. Diagnostic yield of upper gastrointestinal endoscopy in the evaluation of iron deficiency anemia in older children and adolescents. Pediatr Hematol Oncol 2011;28:694-701.

[171] Cohen SA, Klevens AI. Use of capsule endoscopy in diagnosis and management of pediatric patients, based on meta-analysis. Chin Gastroenterol Hepatol 2011;9:490-6.

[172] Fritscher-Ravens A, Scherbakov P, Buffer P, Moroni F, Ruuska T, Nuutinen H, et al. The feasibility of wireless capsule endoscopy in detecting small intestinal pathology in children under the age of 8 years: a multicentre European study. Gut 2009;58:1467-72.

[173] Cohen SA, Ephrath H, Lewis JD, Klevens A, Bergwerk A, Lu S, et al. Pediatric capsule endoscopy: review of the small bowel and patency capsules. J Pediatr Gastroenterol Nutr 2012;54:409-13.

[174] Oliva S, Pennazio M, Cohen SA, Aloi M, Barabino A, Masan C, et al. Caprule endoscopy followed by single balloon enteroscopy in children with obscure gastrointestinal bleeding: a combined approach. Dig Liver Dis 2015;47:125-30.

[175] Casciani E, Nard GD, Chin S, Masselli G, Polettini E, Olive S, et al. MR Enteronraphy in paediatric patients with obscure gastrointestinal bleeding. Eur J Radiol 2017;93:209-16.

Please cite this article in press as: L. Eli, L. Norse, A. Zullo, et al.. Diagnosis of chronic anaemia in gastrointestinal disorders: A guideline by the Italian Association of Hospital Gastroenterologist and Endoscopists (AIGO) and the Italian Society of Paediatric Gastroenterology

Hepatology and Nutrition (SIGENP). Dig Liver Dis (2019), https://doi.org/10.1016/j.dld.2019.01.022 